\title{
A Multi-Agent Energy Trading Competition
}

\author{
Carsten Block, John Collins, Wolfgang Ketter, \\ and Christof Weinhardt
}

\begin{tabular}{|l|l|}
\hline \multicolumn{2}{|l|}{ ERIM REPORT SERIES RESEARCH IN MANAGEMENT } \\
\hline ERIM Report Series reference number & ERS-2009-054-LIS \\
\hline Publication & May 2010 \\
\hline Number of pages & 25 \\
\hline Persistent paper URL & http://hdl.handle.net/1765/17337 \\
\hline Email address corresponding author & wketter@rsm.nl \\
\hline Address & Erasmus Research Institute of Management (ERIM) \\
& RSM Erasmus University / Erasmus School of Economics \\
& Erasmus Universiteit Rotterdam \\
& P.O.Box 1738 \\
& 3000 DR Rotterdam, The Netherlands \\
& Phone: + 31104081182 \\
& Fax: $\quad+31104089640$ \\
& Email: info@erim.eur.nl \\
& Internet: $\quad$ www.erim.eur.nl \\
\hline
\end{tabular}

Bibliographic data and classifications of all the ERIM reports are also available on the ERIM website: www.erim.eur.nl 


\section{RESEARCH IN MANAGEMENT}

\begin{tabular}{|c|c|}
\hline \multicolumn{2}{|c|}{ ABSTRACT AND KEYWORDS } \\
\hline Abstract & $\begin{array}{l}\text { The need for a transition to renewable energy sources will lead to installation of large numbers of } \\
\text { distributed renewable energy generators, which typically produce power intermittently. This trend } \\
\text { conflicts with current power grid control strategies, where a few centralized control centers } \\
\text { manage a limited number of large power plants such that their output meets the energy } \\
\text { demands in real time. As the proportion of distributed and intermittent power production capacity } \\
\text { increases, this task becomes much harder, especially as the local and regional distribution grids } \\
\text { where renewable energy producers are usually installed are currently virtually unmanaged, lack } \\
\text { real time metering and in many cases are not built to cope with power flow inversions. A more } \\
\text { flexible, decentralized, and self organizing control infrastructure must be developed that can be } \\
\text { actively managed to balance both the large grid as a whole, as well as the many lower voltage } \\
\text { sub-grids. One candidate for this control infrastructure is energy markets at the retail level. To } \\
\text { help mitigate the risk of instituting such markets in the real world, we are developing a } \\
\text { competitive market simulation testbed that will stimulate research and development of market } \\
\text { structures along with software agents that can support decision making in these markets. } \\
\text { Participants in the competition will design intelligent agents that will act as brokers, building } \\
\text { portfolios of energy producers and consumers, and matching energy supply from producers with } \\
\text { energy demand from consumers. The competition will closely model reality by bootstrapping the } \\
\text { simulation environment with real historic load, generation, and weather data. }\end{array}$ \\
\hline Free Keywords & $\begin{array}{l}\text { energy trading, market simulation, market design, multi-agent systems, complex networks, } \\
\text { trading agent competition }\end{array}$ \\
\hline Availability & $\begin{array}{l}\text { The ERIM Report Series is distributed through the following platforms: } \\
\text { Academic Repository at Erasmus University (DEAR), DEAR ERIM Series Portal } \\
\text { Social Science Research Network (SSRN), SSRN ERIM Series Webpage } \\
\text { Research Papers in Economics (REPEC), REPEC ERIM Series Webpage }\end{array}$ \\
\hline Classifications & $\begin{array}{l}\text { The electronic versions of the papers in the ERIM report Series contain bibliographic metadata } \\
\text { by the following classification systems: } \\
\text { Library of Congress Classification, (LCC) LCC Webpage } \\
\text { Journal of Economic Literature, (JEL), JEL Webpage } \\
\text { ACM Computing Classification System CCS Webpage } \\
\text { Inspec Classification scheme (ICS), ICS Webpage }\end{array}$ \\
\hline
\end{tabular}




\title{
A Multi-Agent Energy Trading Competition
}

\author{
Carsten Block \\ Karlsruhe Institute of Technology \\ Germany \\ Wolfgang Ketter \\ Rotterdam School of Management \\ Erasmus University, Netherlands
}

\author{
John Collins \\ University of Minnesota \\ USA \\ Christof Weinhardt \\ Karlsruhe Institute of Technology \\ Germany
}

\begin{abstract}
The need for a transition to renewable energy sources will lead to installation of large numbers of distributed renewable energy generators, which typically produce power intermittently. This trend conflicts with current power grid control strategies, where a few centralized control centers manage a limited number of large power plants such that their output meets the energy demands in real time. As the proportion of distributed and intermittent power production capacity increases, this task becomes much harder, especially as the local and regional distribution grids where renewable energy producers are usually installed are currently virtually unmanaged, lack real time metering and in many cases are not built to cope with power flow inversions. A more flexible, decentralized, and self-organizing control infrastructure must be developed that can be actively managed to balance both the large grid as a whole, as well as the many lower voltage sub-grids. One candidate for this control infrastructure is energy markets at the retail level. To help mitigate the risk of instituting such markets in the real world, we are developing a competitive market simulation testbed that will stimulate research and development of market structures along with software agents that can support decision making in these markets. Participants in the competition will design intelligent agents that will act as brokers, building portfolios of energy producers and consumers, and matching energy supply from producers with energy demand from consumers. The competition will closely model reality by bootstrapping the simulation environment with real historic load, generation, and weather data.
\end{abstract}

\section{Introduction}

By 2020, about 35\% of the overall energy demand in the European Union, EU, will be generated through distributed and intermittent "green energy" resources [14]. This presents a severe challenge to the existing energy infrastructure, which was designed to distribute power from a few large generating plants. It is thus very important to adopt a "smart" management approach that will facilitate effective integration of these resources into the existing energy generation and distribution infrastructure. Currently, much of the distributed generation capacity installed is virtually unmanaged, and cannot be supervised form centralized grid control and power dispatch systems.

With a small share of renewables in the overall generation capacity mix, this integration has not been a problem. But this strategy has almost reached its limits. Grid balancing capacities within the European Union for the Coordination of Transmission of Electricity (UCTE) high voltage grid are designed to cope with short-term variations in generator output of at most $3000 \mathrm{MW}$. Planned investments and projects underway in renewable capacity are expected to increase overall production volatility within the next five years to well beyond this level [29]. Furthermore, the number of renewable producers and their wide-spread distribution will strongly increase. In Germany, for example, a roll-out of 100000 distributed Combined Heat and Power (CHP) power plants has begun, with a planned overall installed capacity of $2 \mathrm{GW}^{1}$. A purely centralized command-and-control approach to managing the grid and its generators has reached its limit, with the number of generators and the volatility of their output increasing even further over the next decade.

\footnotetext{
${ }^{1}$ This is roughly the capacity equivalent of two nuclear power plants, see http://www.lichtblick.de/h/idee_302.php
} 
One approach to addressing this problem is to use the resource-allocation power of a market to find a near-optimal balance between producers and consumers of electrical power at lower levels of the grid hierarchy, and to make the participants in this market responsible for near-real-time balancing at the local level. So far, there is limited experience from pilot projects and field studies that could guide design and operation of such regional markets [17,3]. All these projects rely on "intelligent devices" and automation technology to facilitate or even automate energy management at both consumer and producer sites. The automation solutions proposed within these projects are "unchallenged" in the sense that no other (competing) automation technology was deployed within these pilot projects, though competing technologies and solutions will be the default case in large-scale technology deployments on regional or national levels. The California energy market breakdown in 2000 [24, 5] is an example of the problems that can occur if potential strategic, competitive or collusive behavior of market participants is not sufficiently accounted for in the design of such markets.

We describe the design of a competitive simulation environment that will address the need for solid research understanding of a market-based management structure for a local energy grid, which would mirror reality fairly closely. This simulation environment would challenge research teams to create agents [57], or possibly agent-assisted decision support systems for human operators [51], that could operate effectively and profitably in direct competition with each other. Teams would also be challenged to exploit the structure of the market, and that structure would be adjusted periodically to defeat counterproductive strategic behaviors, including those that lead to unused renewable energy, power blackouts, or extreme price volatility. The result would be a body of valuable research data that could guide energy policy, along with a much higher degree of confidence that such a mechanism could be safely introduced into operating energy systems.

We call this vision "TAC Energy" because it is an example of a Trading Agent Competition ${ }^{2}$ applied to energy markets. The main goals of the simulation are (i) to provide a competitive testbed for the development and validation of a market structure for managing electrical power distribution in a local grid, (ii) to spur research and development on intelligent agents and decision support systems that help automate decision processes in such markets, and (iii) to ease knowledge transfer between research and application by providing a testing environment that closely resembles reality. The entities competing in this market will broker electrical power in a local energy grid that contains a mix of intermittent energy sources, with residential, commercial, and industrial demands.

The next section gives background on the structure and organization of current electrical energy production and distribution systems, and reviews previous work both in competitive simulations and in other approaches to addressing the control and resource allocation problems in future energy grids. Following sections explore the published literature that is relevant to this work, and describe major elements of the simulation design in some detail. We then outline the essential decision problems that must be solved by a successful competing agent, and conclude with a discussion of open research questions that can be addressed through a well-designed competitive simulation environment, many of which would be either impossible or highly risky to explore in the real world.

\section{Background and Related Work}

In this section we describe in more detail portions of the existing electrical energy distribution systems that are relevant to the discussion in this paper. We then discuss some of the principal industry and government initiatives that are intended to resolve the problems of integrating new energy sources into the grid, and we review related work in multi-agent modeling and competition testbeds.

\subsection{Energy infrastructure}

Traditionally, the electrical energy infrastructure is organized in a strict hierarchy: A few centralized control facilities manage relatively few large power plants and schedule their production according to forecast energy demands, which are usually based on synthetic load profiles, i.e. average historic consumption time series for different consumer groups. With these estimates at hand, generation capacities are dispatched. Traditionally, power is transmitted from

\footnotetext{
${ }^{2}$ see www.tradingagents.org
} 
power plants to consumers over a network of high and medium voltage transmission grids into low voltage distribution grids that provide the connection to end customers.

With an increasing share of distributed, renewable generation capacities installed in the medium and low voltage grids, production volatility will increase and power flow inversions will occur, which the current technical grid infrastructure and control strategies are not designed for. In parallel, consumers are being equipped with smart metering equipment and demand side management devices (DSM) that help them monitor and actively manage their loads. Consequently, their consumption flexibility will increase and load predictability via synthetic load profiles may become difficult. At the same time they will become at least somewhat responsive to time-varying energy prices.

In order to be able to manage this complex and highly dynamic system, the existing energy grid will have to be transformed into a smart grid with secure real-time ICT integration and communication among all of its components. Based on this information and communication infrastructure, an "Internet of Energy" will evolve [4] that serves as a key enabler for new distributed and highly automated approaches to managing producers, consumer loads and the grid infrastructure.

\subsection{Initiatives}

The U.S. National Institute of Standards and Technology (NIST) recently published the first draft of a "Smart Grid Interoperability Standards Roadmap" [53]. It defines a simplified domain model for a future smart grid with identified "Distribution", "Market," and "Customer" domains being in the core of the overall model. Furthermore a list of prioritized actions for the fast transformation of the current infrastructure into a smart grid is provided. Highest priority, according to NIST, are demand response and consumer energy efficiency measures. In particular they state that "Market information is currently not available to the customer domain. Without this information, customers cannot participate in the wholesale or retail markets. In order to include customers in the electricity marketplace, they need to understand when opportunities present themselves to bid into the marketplace and how much electricity is needed."

In October 2009 the EU Commission announced the Strategic Energy Technology Plan (SET Plan) [14] along with a draft technology roadmap [15]. One of the priority actions mentioned in this roadmap is the development of so called "smart cities" that efficiently and intelligently manage local energy production and consumption. In particular "5-10 development and deployment programmes for smart grids in cities, in cooperation all relevant SETPlan Initiatives, including priority access for local generation and renewable electricity, smart metering, storage, and demand response" should be established within the next two years.

The BDI, a German industry group, has published a technology roadmap that describes the transition from the current energy infrastructure into a so called "Internet of Energy" [4] on a timeline from 2009 to 2020. The document was written by a group of experts from various industries in cooperation with researchers from several different institutions. According to this roadmap, regional energy markets, virtual power plants based on micro CHP turbines, as well as DSM technologies will be mainstream by 2015, and one of the key challenges will be the development of "applications and services for coordinating the energy grid on the business level." In other words, the technical infrastructure will be in place but smart coordination and operation strategies are yet to be developed.

\subsection{Multi-Agent Modeling}

Electricity production and distribution systems are complex adaptive systems [34] that need to be managed in real time to balance the load of an electricity grid. Electricity markets are undergoing a transition from centrally regulated systems to decentralized markets [38]. These transitions are very risky since we do not have sufficient experience in setting up decentralized energy systems and predicting their effect on the economy. We have observed in recent history that failures in designing such systems can cause major damage while deploying them in the real world. The California energy market [5], and the recent collapse of Enron, challenge the wisdom of deregulating the electricity industry, and have demonstrated that the success of competitive electricity markets crucially depends on market design, demand response, capacity reserves, financial risk management and reliability control along the electricity supply chain. Therefore, it is very important to thoroughly test system design proposals in a risk free simulated environment before deploying these ideas into the real world. 
As electricity systems move more toward open, competitive markets, the need for complex modeling systems becomes more obvious. Although traditional optimization and simulation tools will continue to provide many useful insights into market operations, they are typically limited in their ability to adequately reflect the diversity of agents participating in these markets, each with unique business strategies, risk preferences, and decision processes. Rather than assuming we can predict the behavior of market participants, we suggest using agent-based tools in a laboratory setting. This framework will represent electricity markets and market participants using multiple agents, each with their own objectives and decision rules. Agents representing energy producers and consumers, the network operator and the regional wholesale market will part of the simulation environment. The broker agents will be developed by competing research teams, thereby avoiding the cognitive blindness that can limit the value of results arising from non-competitive experimental work in such simulation environments. Intelligent software agents $[57,20]$ offer many possibilities for automating, augmenting and coordinating business decision processes. These agents act on behalf of users, with some degree of independence or autonomy, employing some representation of the user's goals or desires. We focus on enhancing the adaptive learning component of such agents; our research is focused on trading agents that learn to operate effectively in competitive economic environments.

Agent-based modeling and simulation has emerged over the last few years as a dominant tool of the energy sector. For instance, the Electricity Market Complex Adaptive Systems Model (EMCAS) electric power simulation is an agent simulation that represents the behavior of an electric power system and the producers and consumers that work within it [38]. In [47], the authors have developed MAIS, an agent-based decision support system for analyzing and understanding dynamic price changes for the U.S. wholesale electricity market before and during the California energy crisis. Further, energy storage is one of the key underpinnings of the vision of the Smart Grid. In [54], the authors have developed a framework to analyze agent-based micro-storage management for the smart grid. Specifically, they designed a storage strategy (with an adaptive mechanism based on predicted market prices) for consumers and empirically demonstrated that the average storage profile converges towards a Nash equilibrium. Weidlich and Veit [55] survey agent-based market models for wholesale electricity markets, and Zhou et al. [58] review of agentbased simulation tools and their application to the study of energy markets.

The field of Agent-based Computational Economics (ACE) [50] is the computational study of economic processes modeled as dynamic systems of interacting agents. Here "agent" refers broadly to a bundle of data and behaviors that represents an entity in a computationally constructed world. ACE models can support a variety of research agendas, such as understanding and evaluating market designs [32,31], evaluating the interactions of automated markets and trading agents [30], creating rich economic decision environments for human-subject experiments [12], and advising policy makers on the expected behaviors of markets or market interventions [48, 52]. A number of studies have used ACE methods to study electrical power markets, for example [35, 10, 48].

The simulation approach we use extends ACE in the direction of developing strategies and decision procedures for competing agents in modeled market environments. We use the tools and methods of ACE to construct a rich simulated market environment in which one of the agent types faces competition from other agents of the same type. We then invite researchers to implement their own agents to operate in that role, and pit them against each other in the simulated market. This provides a much more rigorous test of the market design, and produces deep knowledge of strategy options and decision procedures for these agents, such as the empirical game theory work of Jordan et al. [23] or the economic-regime work of Ketter et al. [26].

\subsection{Multi-Agent Competitions}

Along with the vision and development of the "Internet of Energy," we identified a lack of automation and intelligent strategies as problems in the future of electricity production and distribution. In this context, agents are a promising tool to help solve these issues. This "TAC Energy" competition will provide a realistic, low-risk platform to effectively test and evaluate agent strategies and decision procedures. Over the last decade competitions are becoming increasingly prevalent in the research world. The current Trading Agent Competitions use a multi-year competition format to study trading in simultaneous online markets (TAC Classic) [56], operation of a three-tier supply chain (TAC SCM) [9, 7], trading of search keywords for advertising purposes (TAC AA) [22], and the operation of online exchanges (TAC CAT) [37]. The TAC CAT market design game explicitly seeks to encourage research in adaptive and automated mechanism design, a topic very closely related to our alternative market structures. CAT entrants compete 
against each other in attracting buyers and sellers and making profits. This is achieved by having effective matching rules and setting appropriate fees that are a good trade-off between making profit and attracting traders. The TAC CAT competition comes in spirit the closet to our TAC Energy competition. All these competitions are examples of crowd-sourcing, i.e. ask multiple, competing participants to innovate solutions to a problem [19].

Each research methodology has strengths and limitations. A well designed competition has many benefits [46]. Much has been learned through designing, developing, and researching TAC SCM over the last eight years. This experience will guide the design of TAC Energy. For instance, one of the awkward features of TAC SCM is the design of the start and end of the scenario; agents start with no inventory at the beginning, and inventory has no residual value at the end of the scenario. TAC Energy will not have these problems, since the broker agents need to balance the grid in real time with extremely limited opportunity to store energy. Another shortcoming of TAC SCM is that the simulation is completely driven using predetermined statistical distributions. These distributions and parameters were carefully designed to balance the game among the three main agent types (supplier, manufacturer, and customer), but nevertheless they have been exploited in unrealistic ways by some research teams, and have generated much discussion among participants about the generalizability of results to real world scenarios. In the TAC Energy simulation we are in the fortunate position to have a large body of real world data from a four year pilot project, MEREGIO, covering 900 households in Germany [18].

TAC Energy has many more potential benefits as a research platform, such as the natural human desire to win. This will be a strong motivation to create a competitive agent by solving the challenges of the domain. Another advantage is that competitions force researchers to build complete, working systems by a specified date. Competitions such as TAC Energy can be strong research drivers for work in specific domains. For example, over the last seven years the annual TAC SCM tournament has pitted autonomous manufacturing agents against each other to determine which is the best performing agent. Each year, results from the previous competition have been published, such as [27, 2, 26], which rapidly raises the bar for research. Since all teams have to solve the same problems in the same domain, this becomes a strong driver for research, and different teams learn from each other. Teams are encouraged to contribute their agents to a shared repository, allowing researchers to run controlled experiments that demonstrate the effect of individual agent designs, such as described by $[23,44]$.

Market liberalization changes the landscape for corporate managers and public policy makers, who face difficulty in both predicting and understanding price changes in electricity markets. Price changes occur due to many uncontrollable factors such as changes in weather conditions, demographic changes, and different trading strategies among traders. Therefore, we need tools to identify and predict market conditions in a dynamic fashion, such as the economic regimes method described in [26].

\section{Competition Scenario}

The competition is focused on the role of a broker acting as an "aggregator" of energy supply and demand, represented by a trading agent. According to von Dollen [53] "aggregators combine smaller participants (as providers or customers or curtailment) to enable distributed resources to play in the larger markets.". In reality brokers could be energy retailers, municipal utilities, or cooperatives; in some cases large utilities could also take on the role of brokers.

Within the competition a broker sells tariff contracts to end customers (e.g. households, small and medium enterprises, owners of electric vehicles), which are attracted or deterred by the respective tariff conditions. Tariff conditions may include flat prices, time of use prices, peak prices, load caps for certain times of the day, contract runtime, etc. In addition to "classical" tariff contracts for energy consumption, a broker can also sell "energy production" tariffs to end customers. Under such a tariff agreement, a customer may be paid for operation of a decentralized energy generator such as a Combined Heat and Power (CHP) plant that feeds power into the grid.

Another type of special customer is Plug-in Electric Vehicles (PEVs). These customers receive special tariff contracts that have separate, time dependent prices for charging the vehicle (consuming energy) and for feeding energy back into the grid (effectively producing energy). As compared to households, PEV customers are comparably large energy consumers during their charge cycle but might decide to discharge some of their stored energy at their own discretion if the power generation prices are sufficiently attractive. Brokers may limit the maximum charge rate for PEVs (e.g. at most 16A), effectively throttling the speed of recharge, and they might encourage PEVs to feed energy back into the grid by setting the generation price appropriately, but they cannot directly enforce charging or 
discharging. This will allow PEV owners (and owners of other types of energy storage capacity) to engage in arbitrage by consuming power when prices are low and producing when prices are higher, thereby offsetting a portion of their capital costs.

On the tactical level (planning horizon: 1 week -3 months) brokers have to manage their portfolios of consumer, producer and PEV contracts. On the operational level (planning horizon: 1 day -1 month) brokers have to balance the fluctuating energy demands of their customers against the actual output of their contracted energy production capacity. Differences can be compensated through balancing power purchased or sold at an energy exchange.

The competition is designed to model most of these challenges, primarily from an economic viewpoint rather than from a technical viewpoint. We use real-world data where it is available, while keeping computational and technical complexity manageable. This design has been developed in consultation with the German energy industry through an expert panel sponsored by the industry group BDI.

In particular we make the following assumptions:

1. Within the simulated region, grid constraints (line capacity limitations) are assumed to be non existent, i.e. power flows within the region are unconstrained. Local distribution grids are typically overdimensioned with respect to their line capacities, thus this assumption is not a strong restriction but may have to be rethought in future once much more distributed generators and storage facilities are installed.

2. The point of common coupling (PCC) between the simulated distribution grid and the higher level transmission grid has a maximum capacity for power inflow and outflow. A specialized agent that serves as a "liquidity provider" on the regional energy spot market, and is able to arbitrage with the national energy spot market, has to obey these technical limits.

3. Power factor effects, i.e. phase shifts between voltage and current, are not taken into account. Modeling these effects would possibly influence the brokers' decision making on which consumers and producers to add to their portfolios but is out of scope at this time.

4. Power distribution and transformation losses are ignored. In Germany these losses are estimated at 3\%; for North America they are estimated at 5,5\% [11]. These losses can be considered as being more or less constant within a distribution grid and identical for all grid participants. Thus the validity of the simulation results is not affected.

5. Two kinds of producers (energy production facilities) are distinguished. One kind (photovoltaic arrays, wind turbines) produce power when active, and are under control of their respective owners. The second kind (PEV batteries, some CHP units) is called "controllable" and may be switched on or off, or have its output adjusted remotely within its capacity range.

6. Technical load balancing (i.e. the real time operations of the local distribution grid) is accomplished outside the action domain of the competition participants (see Section 3.2.2) using a combination of controllable generators and spinning reserves.

7. The simulation will model time as a series of discrete "timeslots" rather than as continuous time. This models the trading intervals in the regional wholesale market, and enables the simulation to model a period of days rather than minutes or hours.

8. The temporal distribution of energy consumption and generation within a timeslot is not taken into account. This means for example that balancing power demand for a timeslot is calculated as the difference of the sum of generation and the sum of consumption for that timeslot and not as the instantaneous difference between the two timeseries.

9. Some portion of the load, including the charging and discharging of Plug-in Electric Vehicles (PEVs), could be controlled by voluntary or automated means, using prospective or real-time price signals.

In order to expose the broker agents to tactical and operational decision making, the competition scenario proceeds through a series of alternating contracting and execution phases as depicted in Figure 1. The number of such phases 


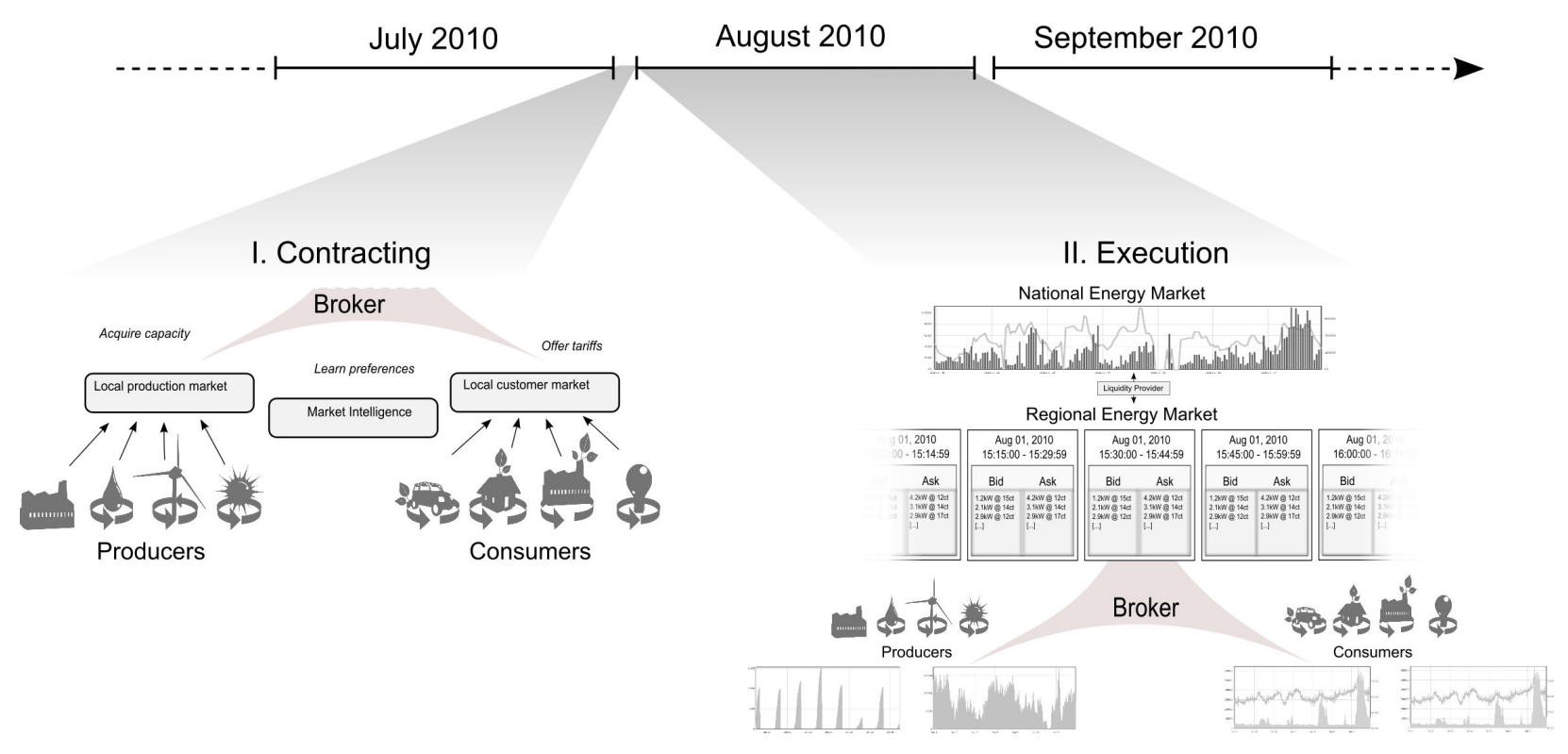

Figure 1: Simulation timeline

will be indeterminate, to prevent strategic behaviors that exploit boundary effects. Both phases are described in more detail in subsequent sections.

To enhance the realism of the competition scenario, we will drive the simulation with real historical data on generation, consumption, and weather information, along with a model of preferences of potential customers derived from customer surveys and pilot projects. One source of such data series is the German MeRegio project, a smart grid project that is implementing a combination of advanced grid control systems and innovative real-time pricing tariffs [18]. The area around Freiamt currently serves as a pilot region for MeRegio; it contains a range of different distributed renewable energy generation facilities in combination with households and small and medium enterprises (SMEs) that are equipped with demand side management devices allowing them to flexibly react to price signals from the distribution grid.

With historic consumption and generation data collected from a region like this, the simulation environment exposes the broker agents to the challenge of managing virtual consumers and producers, which exhibit realistic energy consumption and generation patterns based on the history data.

\subsection{Contracting phase}

On the simulation timeline, a contracting phase represents a short period of time (perhaps 60-120 seconds). During this phase, broker agents try to acquire energy generation capacity from local producers and sell energy tariffs to local consumers. Brokers can buy and sell energy through two different mechanisms. For most customers, such as households, small businesses, and small energy producers, brokers may offer tariffs that specify pricing and other terms. For large producers or consumers (for example, a large industrial facility or a greenhouse complex with many CHP units), brokers may negotiate individual contracts. During a contracting phase, brokers may simultaneously negotiate over individual contracts and offer tariffs as depicted in Figure 2.

Contract and tariff terms and conditions must be described in a language that has clear semantics along with the necessary features to describe a variety of possible business agreements between brokers and their customers. The development of a common semantic model and a common pricing model to describe various kind of energy tariffs are considered top priorities on the EPRI / NIST Smart Grid roadmap for the development of a smart grid [53]. With no common standard in place to build on for TAC Energy, we start with the work of Tamma et al. [49], an ontology that describes a negotiation process including (i) the involved parties, (ii) the object to negotiate on, and (ii) the negotiation process, i.e. the economic mechanism itself. 


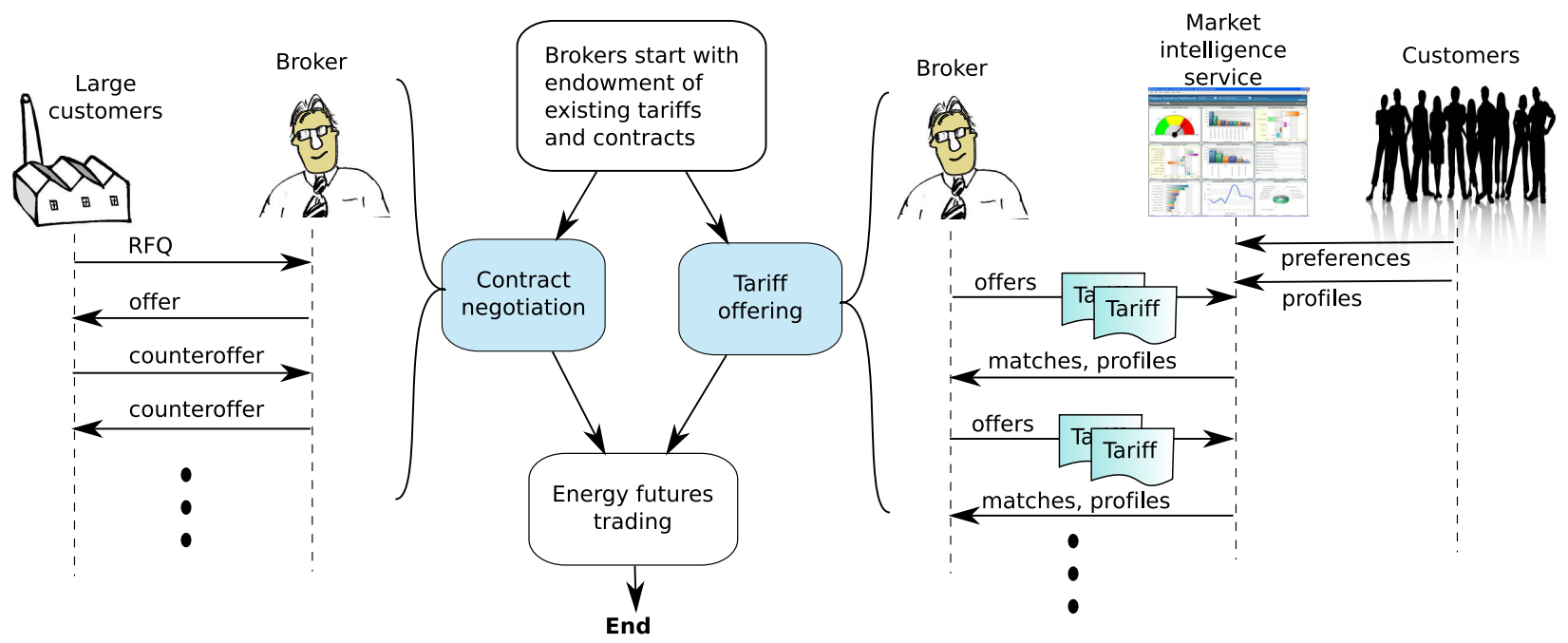

Figure 2: Contracting process. Tariff offerings proceed in parallel with individual contract negotiation.

Within the TAC Energy domain, negotiations and the contracts (including tariffs) that are the subject and result of negotiations must be able to specify

Time: including points in time, time intervals, periodicity (days, weeks, months, etc.), and temporal relationships (before, after, during, etc.). These terms can be used to specify contract duration as well as other time-related contract terms.

Energy: including amounts of energy produced or consumed, and rate of production or consumption (power). Some contracts or tariffs will also need to specify amounts of power that can be remotely controlled, for example by shutting off a domestic water heater for 15 minutes every hour during peak demand periods. Such remotelycontrollable sources or loads are called "balancing power."

Money: Agreements must specify payments to or from the customer based on time (one-time signup fee or bonus, fixed monthly distribution fees), or time and energy (fixed or variable prices for a kilowatt-hour).

Communication: contract award and termination, notification of price changes, etc.

During the contracting phase, a broker must use tariff offerings and contract negotiations to develop a portfolio of contracted consumers and producers. To do this, brokers will need to estimate and reason about consumer and producer preferences in order to design appropriate tariffs and to appropriately respond to Requests for Quotes (RFQs). Brokers will also need to estimate future consumer and producer behavior to build a portfolio that has well-balanced demand and supply over time and that provides sufficient balancing capacity to achieve an acceptably low risk of executiontime imbalance.

Commonly, companies delegate the tasks of determining customer preferences and estimating business potential for new products (tariffs) to their marketing departments, or they outsource them to specialized service providers. Within the competition scenario, brokers may request such information from the market intelligence service (c.f. Fig. 2). This service is used somewhat differently for developing tariffs and individual contracts, as described in the next sections.

The market intelligence service also provides brokers with historic consumption time series for all consumers and producers already under contract. With these time series at hand, a broker will be able to estimate how much generation and consumption capacity will be available over time and whether its portfolio is well balanced. Figure 3 shows an example of such a historic time series for a wind turbine with a nominal capacity of $150 \mathrm{~kW}$. 


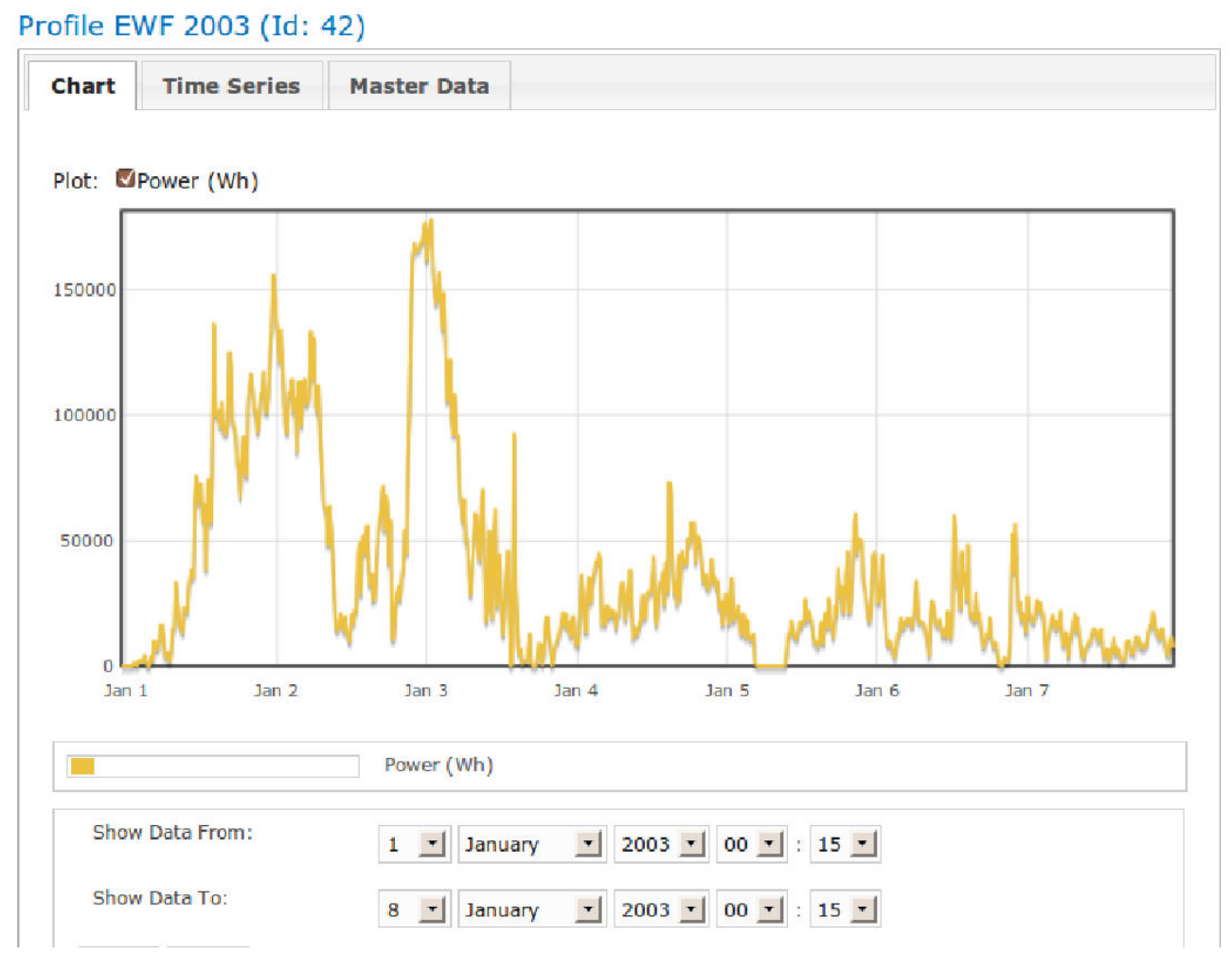

Figure 3: Sample wind turbine generation timeline as provided by the market intelligence service.

\subsubsection{Negotiating tariffs}

Tariffs are offered contracts that can be accepted or not by anonymous energy consumers and producers. The problem faced by broker agents in a competitive market is how to know whether a particular tariff will "sell." What happens in the real world is that firms are continually bidding against each other, attempting to attract the most "desirable" customers with their offerings.

One way to simulate this process is to allow brokers to offer tariffs in multiple "rounds," with the number of rounds $|\mathcal{R}|$ indeterminate to prevent "sniping" attacks. In each round $r \in \mathcal{R}$, agents are permitted to add or withdraw tariffs from their current offerings, resulting in a set of tariffs $\mathcal{U}_{r}$ for round $r$. The market intelligence service then runs a customer preference model (under development) to allocate customers to offered tariffs. Each agent is then provided with the number of customers who would agree to each of their offered tariffs, and they may then query the market intelligence service for predicted "demand profiles" for the projected customer base associated with each of their currently offered tariffs. These are simply aggregated time series for the set of customers who currently prefer the individual tariffs. At the end of the last round, no more offerings may be made, and brokers are charged a fee for each concurrently offered tariff. In other words, in each round $r$, a set of tariffs $\mathcal{U}_{b, r}$ is offered by broker $b$. If the fee for offering a tariff is $p^{\text {fee }}$, then the total tariff fee $p_{b}^{\text {fee }}$ for broker $b$ in the current contracting cycle will be

$$
p_{b}^{\mathrm{fee}}=p^{\mathrm{fee}} \max _{\mathcal{R}}\left(\left|\mathcal{U}_{b, r}\right|\right), \forall r \in \mathcal{R} .
$$

At the end of the last round, all currently-offered tariffs will be available for inspection by all agents through the market intelligence service.

The customer preference model aggregates a realistic range of household and business models. The function of the Market Intelligence Service is not to "clear" the market in any sense, but rather to simply reflect the aggregate behavior of a population of agents with a range of preferences. As in the real world, individual customers will act in their own interest, even if that interest means that they are not paying attention to the cost of their electrical power at 
any particular time. In other words, every customer always has a tariff that they have agreed to in the past, and new tariff offerings from brokers may fail to attract the attention of most customers. This will protect the tariff market from large swings, and will prevent a single broker from cornering the market easily.

\subsubsection{Negotiating individual contracts}

Individual contracts are negotiated through an RFQ process, initiated by service providers (producers and consumers of power), and proceeding through one or more rounds with as many agents as continue to be interested. The process ends when any party accepts the current contract, or when either the RFQ originator or all brokers choose to withdraw. The smallest entities that will engage in this process will have capacities of at least 100 times the mean demand of individual households. The specifics of the negotiation process are undefined at this point, but there are many examples in the literature, such as [21].

\subsection{Execution phase}

During an execution phase (see Figure 4), each broker must manage the supply and demand resources acquired during the contracting phase over a set of at least seven consecutive simulated days. Besides strong diurnal effects energy demand also differs significantly between working days and weekends. The length of seven days ensures an inclusion of both type of days within each execution phase. The exact length of an execution phase is drawn from a random distribution but is not revealed in advance to the agents, to reduce boundary effects within the competition.

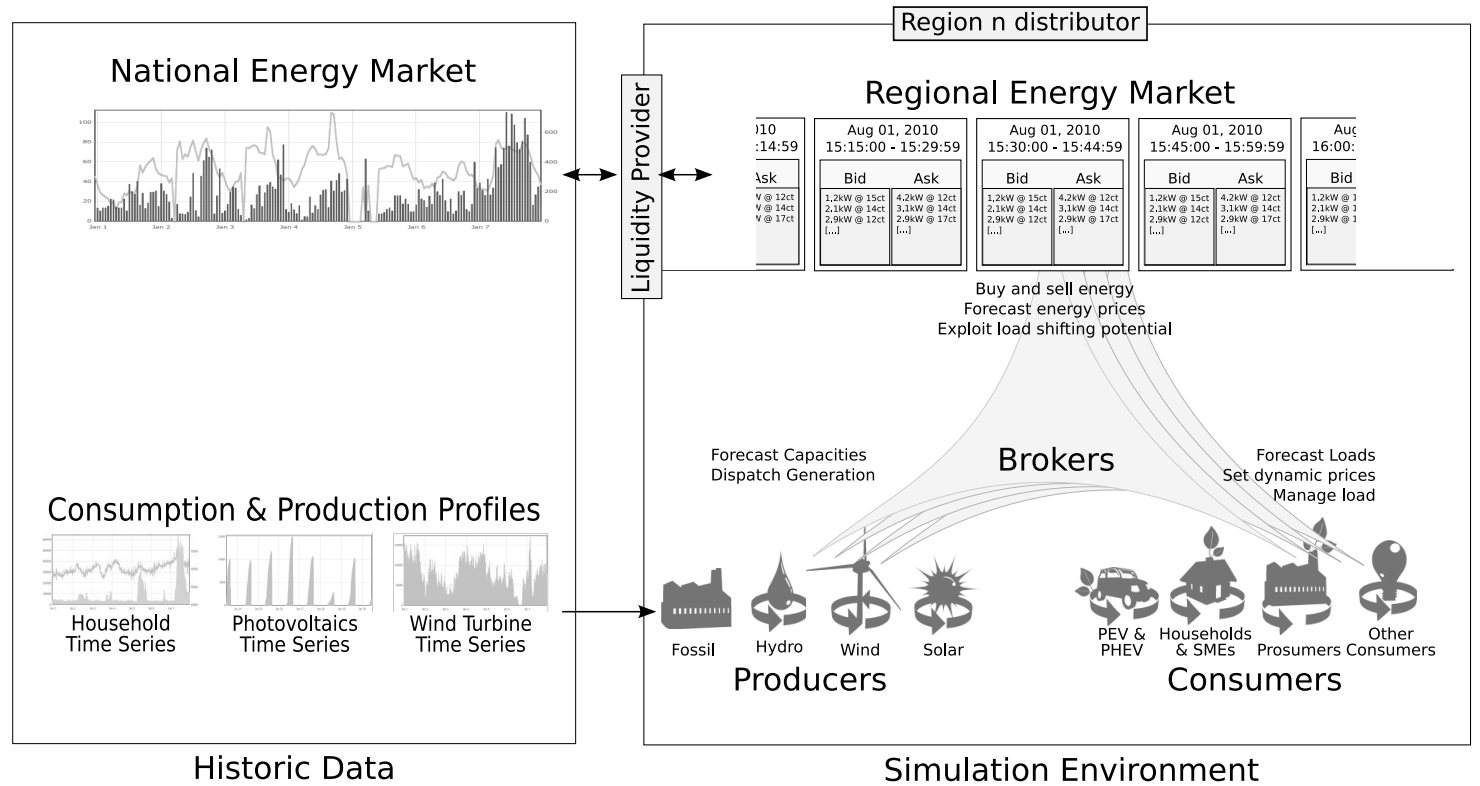

Figure 4: Execution phase

The broker's main task during this timespan is to balance his customer and producer portfolios. The broker needs to ensure that the total energy demand and supply of the consumers and producers in his portfolio are balanced at any given point in time throughout the whole execution phase. Deviations between production and consumption might still occur but will be charged an (expensive) balancing power fee. The total energy consumption for broker $b$ in timeslot $s$ is

$$
e_{c}(b, s)=e_{\mathrm{ex}}(b, s)+\sum_{i=1}^{\left|\mathcal{C}_{b}\right|} e_{i}(s)
$$

or the sum of the loads during timeslot $s$ of each energy consumer in the set $\mathcal{C}_{b}$, the consumers in the portfolio of broker $b$, plus the energy exported from the grid by broker $b$ during timeslot $s$ through sales commitments in the 
regional energy market (see Section 3.2.3). Similarly, the total energy production for broker $b$ in timeslot $s$ is

$$
e_{g}(b, s)=e_{\mathrm{im}}(b, s)+\sum_{j=1}^{\left|\mathcal{G}_{b}\right|} e_{j}(s)
$$

or the sum of outputs during timeslot $s$ of each energy producer in the set $\mathcal{G}_{b}$ of producers in the portfolio of broker $b$, plus the energy imported by $b$ through purchase commitments in the regional energy market.

In this context, balance between supply and demand means that supply equals demand for each broker in each timeslot,

$$
\forall s \in \mathcal{S}, e_{g}(b, s)-e_{c}(b, s)=0
$$

Note that $e_{g}(b, s)$ can include an arbitrary portion of contracted balancing power, and $e_{c}(b, s)$ may include an arbitrary portion of contracted controllable load as we shall see in Section 3.2.2. Ultimately, it is the job of the Independent System Operator (ISO, part of the simulation) to ensure exact balance between supply and demand in real time. Any imbalance remaining after summing supply and demand across all brokers will be balanced by the ISO using its own resources (for example, it could start up a gas turbine) and charged to the brokers who are responsible for the residual imbalance.

A broker's consumer and producer portfolio (i.e. the set of contracts) remains stable throughout an execution phase, but the overall energy demand and supply within the portfolio is volatile over time. The reason is that the actual behavior of producers and consumers is modeled based on historic generation or consumption profiles of corresponding real world entities. A wind turbine under contract with a broker will be bootstrapped with a historic time series data of a real wind turbine. Figure 3 shows an example for such a time series. The wind turbine modeled within the competition will expose the same significant generation volatility over time as its real world counterpart did; the same applies to consumers.

\subsubsection{Collecting information and predicting the future}

As during the contracting phase, a broker may request historic time series data for the seven preceding days (i.e. the approximate length of one complete execution phase) from the market intelligence service for all producers and consumers currently under contract. With this historic data series at hand a broker will be able to build its own prediction model for future energy consumption and production of its portfolio, in order to be able to detect and address likely future imbalances.

In general, retrieval of future time series data from the market intelligence service is not permitted throughout the competition with one exception: For intermittent generators such as photovoltaics or wind turbines, the estimation of future output solely based on historic time series data is problematic and unrealistic. Predictions about the output of these types of generators are usually based on weather forecasts as described for example in [40].

In order to shield brokers from having to model weather forecasts, and also because forecasts for specific generators as input for the competition are usually not publicly available ${ }^{3}$ the approach for this competition is to permit future time series data lookups (only) for intermittent generators. Still, in order to model reality closely, these future time series will be artificially distorted (see [1] for background).

Instead of returning the exact future energy production time series for a generator $j$, the simulation will return an artificial (forecasted) production $e_{g}^{\prime}\left(j, s_{k}\right)$ for each time slot $s_{k},(n+1) \leq k \leq \eta$ from the currently running time slot $s_{n}$ up to a future time slot $s_{\eta}$. Each forecasted generation capacity $e_{g}^{\prime}\left(j, s_{k}\right)$ is calculated as:

$$
e_{g}^{\prime}\left(j, s_{k}\right)=e_{g}\left(j, s_{k}\right)\left(1+\zeta_{g}\left(j, s_{k}\right)\right), s_{n} \prec s_{k} \preceq s_{\eta}
$$

where $\zeta_{g}\left(j, s_{k}\right)$ represents a forecasting error for the generation capacity of generator $j$ in time slot $s_{j}$. For example, if $\zeta_{g}\left(j, s_{k}\right)=0.05$ for generator $j$ during timeslot $s_{k}$, then the prediction will be 5\% higher than the actual output. The forecasting error $\zeta_{j}\left(j, s_{k}\right)$ is computed using a stochastic process, in particular a Wiener process [39].

$$
\zeta_{j}\left(j, s_{k}\right)=\varepsilon_{k}+\alpha \sum_{i=n+1}^{k-1} \varepsilon_{i}
$$

\footnotetext{
${ }^{3}$ Such forecasts are provided by specialized companies that charge significant fees.
} 
Variable $\alpha$ is used to adjust the autocorrelation between two forecasts for generation capacity in adjacent time slots. Setting $\alpha=1$ results in a perfect positively autocorrelated time series while $\alpha=0$ leads to a completely uncorrelated time series. In order to produce realistic forecasts, $\alpha$ needs to be adjusted manually for each time series (each type of intermittent generator) for which we wish to create forecasts. The noise variable $\varepsilon_{i}(n+1 \leq i \leq k-1)$ is normally distributed $\varepsilon_{i} \sim N\left(0, \sigma_{i}\right)$ and the standard deviation $\sigma_{i}$ is defined as:

$$
\sigma_{i}=\phi_{1} \cdot \frac{\sqrt{2 \pi}}{2} \cdot \frac{\left(\eta+i \frac{\phi_{\eta}}{\phi_{1}}-i-\frac{\phi_{\eta}}{\phi_{1}}\right)}{\sqrt{1+\alpha^{2} \cdot i-\alpha^{2} \cdot(\eta-1)}}
$$

The result of this process is that predictions of the future become progressively less accurate as the time horizon increases. We can model this process by considering the mean absolute percentage error (MAPE) of a prediction. $\phi_{1}$ is assumed to be the mean absolute percentage error (MAPE) of a production forecast in the first forecasted time slot $\left(s_{n+1}\right)$, and $\phi_{\eta}$ is the MAPE for production in the last forecasted time slot $s_{\eta}$. The expected errors $\phi\left(s_{k}\right)$ for the time slots $s_{k},(n+1)<k<\eta$ are linearly interpolated by this process:

$$
\phi\left(s_{k}\right)=\phi_{1}+\left(\phi_{\eta}-\phi_{1}\right) \frac{k-1}{\eta-1}
$$

The idea for the creation of this type of artificial forecasts originally stems from [1] and is described there in detail.

Based on (i) the historic generation schedules of "predictable" generators (e.g. micro turbines or CHP plants), (ii) the historic consumption schedules of the consumers under contract, and (iii) the forecasted generation schedules of intermittent generators, a broker will have to predict the estimated future energy generation and consumption schedules for its portfolio as visualized in Figure 5. Note how the uncertainty for the expected demand and supply in time slots far into the future is higher than for those near to the current time slot. In Figure 5(a) the maximum expected overall generation capacity for broker $b$ in time slot $s_{n+5}, e_{g}^{\prime}\left(b, s_{n+5}\right)$, is much lower than the expected overall load $e_{c}^{\prime}\left(b, s_{n+5}\right)$. But as the MAPEs for both numbers are high (indicated as gray boxes), the accuracy of this prediction is low. ${ }^{4} 120$ Minutes later (Figure 5(b)) the expectation values for supply and demand remained unchanged but the standard deviation decreased. At this point in time the broker is able to predict an excess demand situation (e.g. see [26]) for the time slot with a good confidence and thus can now already introduce appropriate countermeasures. In this case he decided to acquire additional energy for time slot $s_{n+5}$ from the regional energy exchange as indicated in the Figure. An alternative would be to adjust energy and supply within $b$ 's portfolio as described in the following section.

\subsubsection{Adjusting energy demand and supply}

For each time slot $s$, each broker $b$ must balance expected supply and demand closely enough that the ISO can achieve exact balance without expending any of its own resources. Expected demand is the total expected load, or the sum of committed power exports and the expected loads $e_{i}^{\prime}(s)$ of each consumer $i$ in the broker's consumer portfolio $\mathcal{C}_{b}$ during time slot $s$ (see Equation 2):

$$
e_{c}^{\prime}(b, s)=e_{\mathrm{ex}}(b, s)+\sum_{i=1}^{\left|\mathcal{C}_{b}\right|} e_{i}^{\prime}(s)
$$

Expected supply is committed power imports plus total expected production capacity of all generators $g$ within the broker's portfolio $\mathcal{G}_{b}$ during timeslot $s$ (see Equation 3):

$$
e_{g}^{\prime}(b, s)=e_{\mathrm{im}}(b, s)+\sum_{j=1}^{\left|\mathcal{G}_{b}\right|} e_{j}^{\prime}(s)
$$

These values are maximum values in case some consumers and/or some producers in the broker's portfolios have agreed to external control, presumably in exchange for better prices. For example, a combined heat and power generator with a nominal output of $50 \mathrm{~kW}$ can be adjusted by an external control so that its real production is within certain

\footnotetext{
${ }^{4}$ Note that the MAPE for the overall consumption stems from the demand forecasting model the broker has to build on its own. The MAPE for the overall generation stems in part from the artificial distortion of future generation data as described in this section and in part from a generation prediction model that the broker has to implement for forecasting its non intermittent generation capacities like e.g. CHP engines or micro gas turbines
} 
boundaries, e.g. $[40 \mathrm{~kW}-50 \mathrm{~kW}$. Similarly, a domestic water heater may be configured to permit remote shutoff for up to 15 minutes every hour. The total controllable load for a broker $b$ during timeslot $s$ is $\epsilon_{c}(b, s)$, and the total controllable production capacity is $\epsilon_{g}(b, s)$. As long as $e_{g}(b, s)-\epsilon_{g}(b, s) \leq e_{c}(b, s)$ and $e_{c}(b, s)-\epsilon_{c}(b, s) \leq e_{g}(b, s)$, then supply and demand during timeslot $s$ is expected to be in balance. Within this range, the ISO will either reduce load or reduce output as needed to achieve exact balance.

The dispatching of balancing power (or load) by the ISO is done only during the current simulation time slot $s_{n}$. In Figure 5(a), we can see in the current slot $s_{n}$ that both the actual observed supply and demand have deviated from the forecasted overall supply and demand for broker $b$. But as the difference between $e_{c}\left(b, s_{n}\right)$ and $e_{g}\left(b, s_{n}\right)$ was smaller than $\epsilon_{g}\left(b, s_{n}\right)$, the controllable production capacity of broker $b$ in this slot, the ISO was able to automatically reduce supply such that overall demand and supply for timeslot $s_{n}$ was rebalanced.

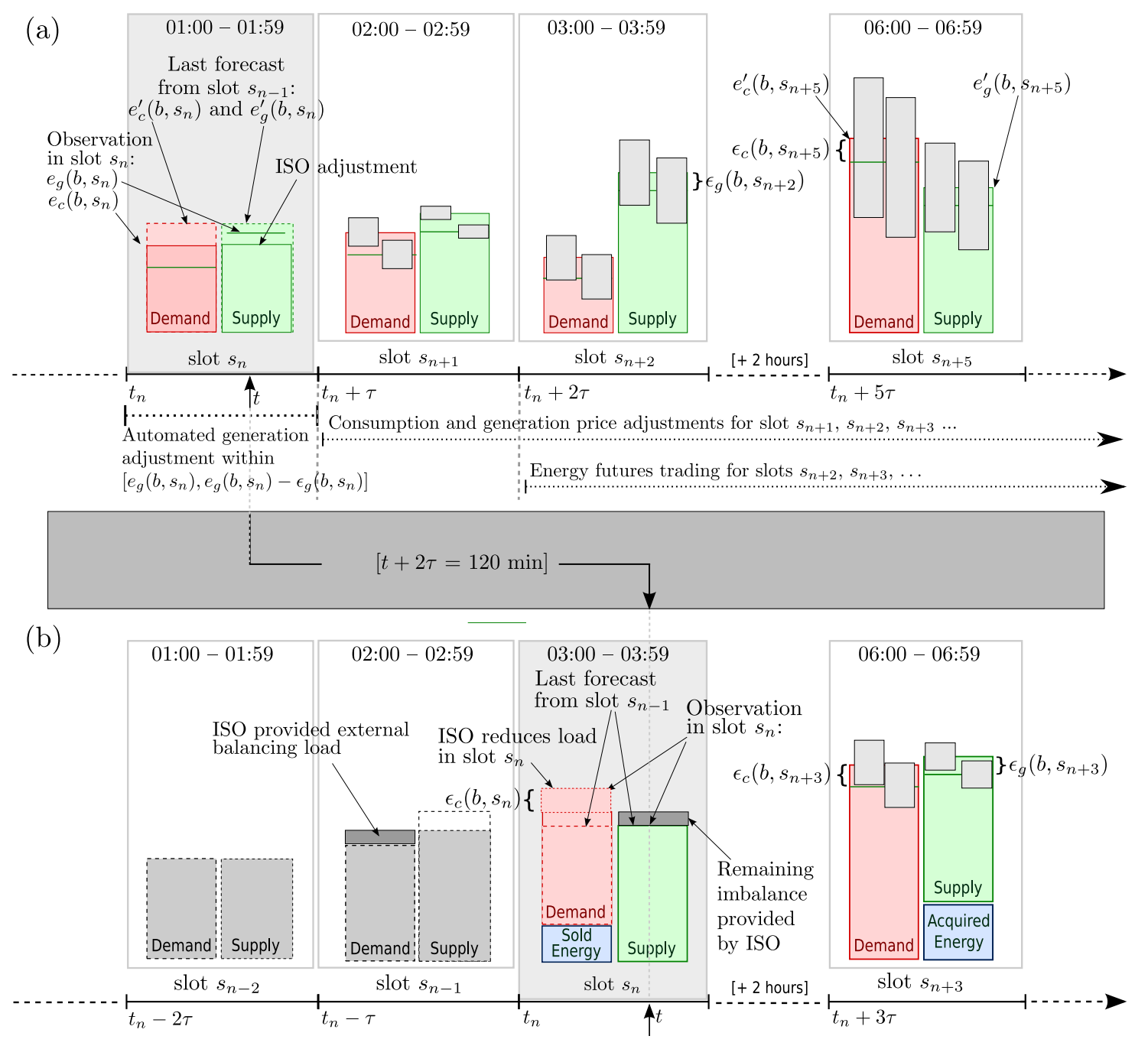

Figure 5: Broker's expected and actual energy supply and demand at two points in time.

For time slot $s_{n+1}$ in Figure 5(a), expected overall demand is forecasted to be within range of the available production capacity, but the uncertainty envelope (grey boxes) shows that this is not certain. In other words words $e_{g}^{\prime}\left(b, s_{n+1}\right)-\epsilon_{g}\left(b, s_{n+1}\right) \leq e_{c}^{\prime}\left(b, s_{n+1}\right)$. After $2 \tau$ simulation time has elapsed (Figure 5(b)), this slot is now designated $s_{n-1}$, and we can see that the real consumption $e_{c}\left(b, s_{n-1}\right)$ in this time slot turned out to be lower than $e_{g}\left(b, s_{n-1}\right)-\epsilon_{g}\left(b, s_{n-1}\right)$. This means that even after the simulation environment reduced the broker's production ca- 
pacity to its minimum level, the overall production still exceeded the overall consumption. In this case the ISO used an external balancing load (either a shortage of power from some other broker, or something like a large pumped-storage power plant outside the broker's portfolio) to absorb the excess generated energy. In the energy industry this type of balancing power is usually called an "ancillary service" and its utilization is billed to the broker at a defined (high) price.

In slot $s_{n+2}$ in Figure 5(a), a significant difference between overall production and overall consumption is forecast. Internal balancing capacity is likely to be insufficient for leveling the expected difference. In order to avoid the (expensive) utilization of external balancing power, broker $b$ can either sell some of its surplus energy on the exchange, or use its contracted pricing power to try to encourage (i) some or all of its consumers to increase their demand, or (ii) some or all of its producers to reduce their production. Technical adjustments (e.g. a remote activation of loads at consumer premises) is not allowed within the competition. But a consumer's energy consumption is subject to the energy consumption price for consumer $i$ in a time slot $s$, which is defined as $p_{c}(i, s)$. We define

$$
\hat{e}_{c}\left(i, s_{n+2}\right)=e_{c}^{\prime}\left(i, s_{n+2}, p_{c}\left(i, s_{n+2}\right)\right)
$$

as the predicted load for consumer $i$ in time slot $s_{n+2}$, given price $p_{c}\left(i, s_{n+2}\right)$. If the broker changes the underlying consumption price to $p_{c}^{\prime}\left(i, s_{n+2}\right)$ the forecasted consumption of this consumer is expected to increase as

$$
\hat{e}_{c}^{\prime}\left(i, s_{n+2}\right)=e_{c}^{\prime}\left(i, s_{n+2}, p_{c}^{\prime}\left(i, s_{n+2}\right)\right)
$$

The ratio of demand change to price change

$$
P E_{i}=\frac{\hat{e}_{c}(i, s, p)-\hat{e}_{c}\left(i, s, p^{\prime}\right)}{p-p^{\prime}}
$$

is called the "price elasticity" for consumer $i$. Price elasticities will have to be modeled within the different consumer agents provided by the competition environment following empirical findings on price elasticity as decsribed for example in $[45,43]$.

Some producers in the broker's portfolio (such as electric vehicle batteries that can be discharged into the grid) might have agreed to flexible pricing as well, and therefore their output will be sensitive to price in a similar way. In other words, the power generation capacity of broker $b$ in time slot $s, e_{g}(b, s)$, is likely to change if the generation price $p_{g}(j, s)$ is changed to $p_{g}^{\prime}(j, s)$, decreasing if $p_{g}^{\prime}(j, s)<p_{g}(j, s)$.

We have implemented different kinds of customer models within our experimental framework, such as electric vehicles, CHPs, wind turbines, and private households. As an example Figure 6 shows the difference between the electricity load profile of a household's washing machine under a flat tariff and under real-time pricing. A simulation tool generates the load profile of a household for one year under a flat tariff by using historical data. For shifting it is assumed that customers face real-time electricity prices. The simulation shifts the use of each device to the cheapest time slot within a day under consideration of customer preferences.

For estimating the load profile of a household the consumption share of a device on the total yearly electricity consumption of a four person household is used. Historical mean values for yearly electricity consumption and the share of a device on this consumption are used. Yearly load per device and the consumption of a device enable to calculate the number of runs for each device. The runs are distributed on different time slots of a year. Each season, day of the week and time of the day has different probabilities for the allocation of device runs. Additionally, the presence of the persons living in the household is determined and for some devices (e.g., washing machine, dish washer) the calculated start slot for a run is updated if no one is at home.

In the shifting simulation for the washing machine it is assumed that a household loads its washing machine in the morning between 5:30 and 7:30, for all machines started after 5:30 am. For a wash that started between 0 am and 5:30 am under the flat tariff the point of loading does not change. After loading the machine the customer selects a time period in which the wash should finish. There are four modes available: finish within the next 5 hours, between 5 to 10 hours from now, after 10 hours from now or the wash can be done at each time slot during that day. Selection of a mode is based on the presence of the household occupants. A mode can only be selected if a customer is at home during the two hours after the end of the interval specified by a mode. Next, the simulation determines the cheapest period for running the washing machine, which must be within the interval set by the selected mode. $66 \%$ of the washes have to be finished before 10:30pm as $66 \%$ of the German population are asleep at $11 \mathrm{pm}$. 


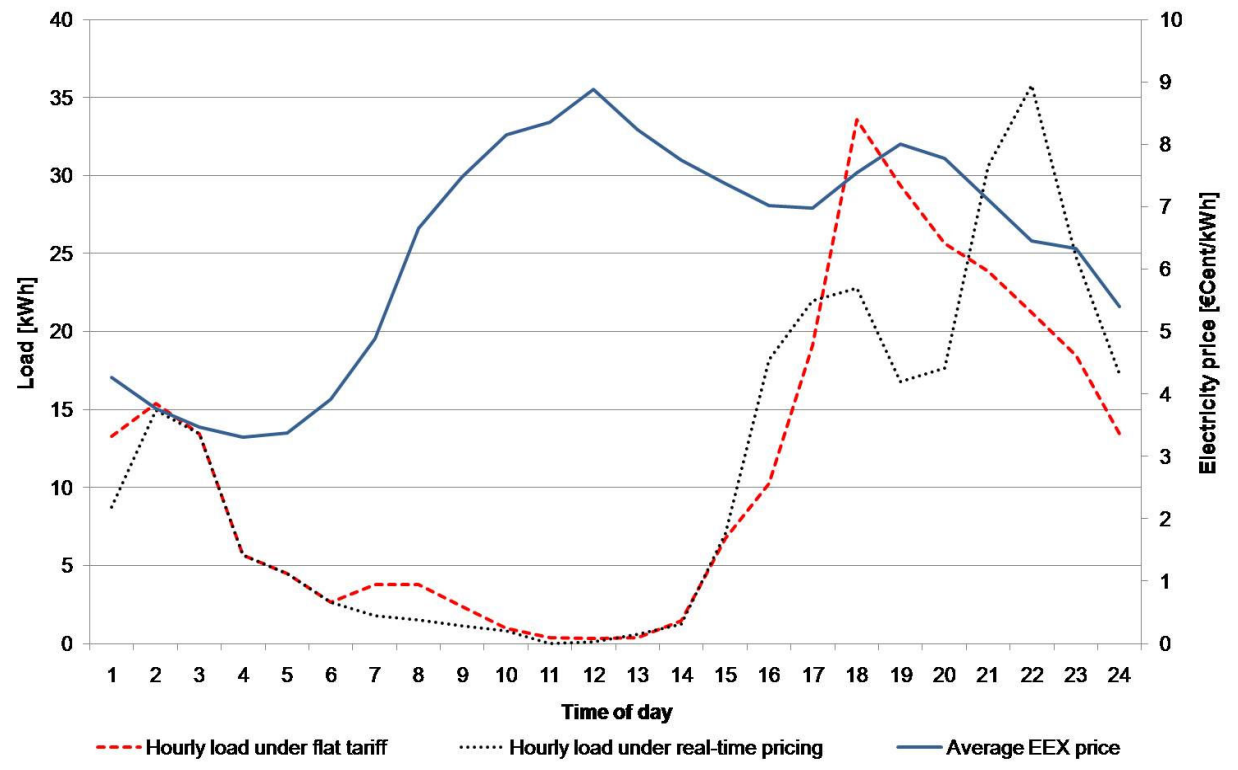

Figure 6: Demand shifting of a household washing machine.

Figure 6 sums the load corresponding to a washing machine in each hour during the whole year under a flat tariff and under real-time pricing. The average European Energy Exchange (EEX) price curve explains the differences between the two load curves: in times of high prices load is reduced, meanwhile a load increase in low period prices can be observed.

\subsubsection{Buying or selling futures on the energy market}

The re-adjustment of energy prices for consumers and producers as well as the advance reservation of (partial) producer capacity as balancing power reserves are two possibilities to level out a broker's portfolio over time. Besides these two options, a third one is to buy missing or to sell excess capacities on the energy market. Within the competition this market is modeled as a continuous double auction with uniform pricing and thus resembles the prevalent mechanism design in place for energy spot market trading in Europe and North America [33]. On this market standardized energy futures are traded. An energy future is a binding commitment to consume or to produce a defined amount of energy (e.g. 1kWh) within a defined future time slot (e.g. Aug 01, 2007, 03:00 - 03:59) at a defined price (e.g. $20 \mathrm{ct} / \mathrm{kWh}$ ). In order to buy or sell energy futures, a market participant sends bid or ask orders to the energy market, which then clears (matches) all incoming bids and asks at a uniform price determined according to the the maximum turnover needed principle (see e.g. [13] for a detailed description of the mechanism).

Table 1 shows a sell order before its submission to the energy market (left) and after its clearing (right). In this example Broker 1 wants to sell $10 \mathrm{kWh}$ of Power within the time slot Aug 01, 2007 03:00 - 03:59 at a minimum price of $0.14 \mathrm{EUR} / \mathrm{kWh}$. The offer is set to expire on Aug 01, 2007 01:52h, i.e. if no matching takes place until that time, the order will be canceled. at 01:37 the order is matched on the energy market at a price of $0.15 \mathrm{EUR} / \mathrm{kWh}$ and a quantity of $100 \mathrm{kWh}$. Broker 1 managed to sell $100 \mathrm{kWh}$ of energy for this time slot, which helps him to better balance his portfolio's overall energy supply and demand in this time slot (see Figure 5).

Besides the brokers trading energy futures on the regional energy market, there is also a special agent called "liquidity provider." The liquidity provider is basically representing the point of common coupling (PCC) between simulated region and national grid on the regional market. He can buy energy at the national market and transfer it via the PCC to the simulated region and vice versa. Thus the liquidity provider serves as an arbitrage agent that levels prices of the regional and the national energy market and constitutes an explicit market coupling [33]. 
(a) Submitted Sell Order

\begin{tabular}{|ll|}
\hline Order ID: & 1 \\
Order Owner: & Broker 1 \\
Timeslot: & Aug 01, 2007 03:00 - 03:59 \\
Order Type: & Sell \\
Order Status: & Open \\
Quantity: & $100 \mathrm{kWh}$ \\
Limit: & $0.14 \mathrm{EUR} / \mathrm{kWh}$ \\
Created at: & Aug 01, 2007 01:37 \\
Valid Until: & Aug 01, 2007 01:52 \\
Clearing Date: & - \\
Clearing Quantity: & - \\
Clearing price: & - \\
\hline
\end{tabular}

(b) Matched Sell Order

\begin{tabular}{|ll|}
\hline Order ID: & 1 \\
Order Owner: & Broker 1 \\
Timeslot: & Aug 01, 2007 03:00 - 03:59 \\
Order Type: & Sell \\
Order Status: & Matched \\
Quantity: & $100 \mathrm{kWh}$ \\
Limit: & $0.14 \mathrm{EUR} / \mathrm{kWh}$ \\
Created at: & Aug 01, 2007 01:37 \\
Valid Until: & Aug 01, 2007 01:52 \\
Clearing Date: & Aug 01, 2007 01:42 \\
Clearing Quantity: & $100 \mathrm{kWh}$ \\
Clearing price: & $0.15 \mathrm{EUR} / \mathrm{kWh}$ \\
\hline
\end{tabular}

Table 1: Orders submitted to and later matched on the regional energy market.

\section{Agent decision problems}

Brokers in the simulation may be individual autonomous learning agents, as in TAC SCM $[9,26]$. They may also be agent communities; for example, it might make sense to separate the contracting and execution behaviors into two separate agents. It is also possible that the "agent," at least for the contracting phase, could be one or more human decision-makers operating with the assistance of appropriate user interfaces and decision-support tools. This section describes in some detail the decisions such broker agents must make to operate within the TAC Energy simulation. We will separate the discussion into the Contracting and Execution phases as described in the previous section. There is very little overlap between the behaviors and decisions during these two phases, except that (i) both phases allow trading in the regional spot market, and (ii) the decisions made during the contracting phase will profoundly influence the required behaviors during the following execution phase.

\subsection{Contracting phase}

The primary goal of the contracting phase is to acquire access to power sources and customers that result in a portfolio that is profitable and balanced, at least in expectation, over the period of the next execution phase. A secondary goal is to manage financial and supply/demand imbalance risks. For example, an agent will benefit from having reasonably-priced energy sources that can be expected to produce power when demand is expected to be highest within its load portfolio. Predictability is also important, and will generally improve both with volume (because noise as a proportion of demand or supply will be lower with larger numbers of randomly-behaving sources and load, even if they are correlated) and with a balanced portfolio of uncorrelated sources and loads. Risk can be managed by acquiring uncorrelated sources and loads that can be expected to balance each other in real time, by acquiring storage capacity, by acquiring sources that can be used as needed (balancing sources), and by trading futures contracts on the regional exchange.

At the beginning of a contracting phase, an agent will have some number of contracts in force, having negotiated them earlier. Such contracts have expiration dates beyond the current date. Also, tariffs offered earlier may remain in force; customers who have agreed to a tariff in the past may or may not have an opportunity to opt out and choose a different tariff, and if they have the opportunity they may not choose to exercise it.

\subsubsection{Acquire power sources}

Power source commitments are obtained by three different methods:

- Large local sources (large wind turbines, wind farms, large CHP plants, etc.) are traded in the local market through the RFQ process as described in Section 3.1.2.

- Small local sources (household and small-business sources) are obtained by offering tariffs in the local market, as described in Section 3.1.1.

- Power from the regional grid is obtained by trading in the regional exchange. 
Power sources can be continuous or intermittent, and local continuous sources may have a non-zero balancing component as discussed in Section 3. Continuous sources include power obtained from the regional exchange, as well as the continuous portion of the output from many CHP and hydro plants. Intermittent sources include most renewable sources such as wind and solar plants.

\subsubsection{Acquire storage capacity}

Storage capacity can be used to absorb excess power or to source power during times of shortage. Power can be absorbed by capacity that is not fully charged, and sourced by capacity that is above its contracted minimum charge level. Storage capacity that is below its minimum charge level is considered to be a load that is possibly responsive to real-time price signals.

Storage capacity can be contracted through the local market through the tariff or the RFQ process. For example, individual owners of PEVs could sign up for tariffs that provide for both charging of the batteries as well as limited discharging as needed for load balancing by the contracted broker. On the other hand, a battery-exchange service for electric vehicles might negotiate a contract for the use of a portion of its current battery inventory for balancing purposes.

\subsubsection{Acquire loads}

Loads may be contracted through both the local market and the regional exchange, as is the case with power sources.

- Large local loads (industrial facilities and large office parks, for example), could negotiate rates through the RFQ process.

- Small local loads (households and small businesses, for example) must choose tariffs in the local market.

- Agents may choose to sell future power capacity in the regional exchange for periods when it expects to have a surplus. Such advance sales are hard commitments; the sold quantity of power will be transferred out of the system during that interval at a constant rate.

\subsection{Execution phase}

A detailed timeline of events prior to and during the execution phase is shown in Figure 7. At time $t$, the simulation is partway through one of the 60-minute timeslots defined by the regional exchange, which started in the past at time $t_{n}$. Trading has closed on that slot, and on slot $s_{n+1}$. Trading will close on slot $s_{n+2}$ at the beginning of slot $s_{n+1}$ at time $t_{n}+60$. Between time $t$ and time $t_{n}+60$, the agent may continue to trade in slot $s_{n+2}$ and all future slots. The agent may also send price signals to its contracted loads and sources at any time, to the extent allowed in their respective contracts. At the end of each slot (time $t_{n}+60$ in this example), the agent will receive information about its supply and demand status at the end of the just-completed slot (slot $s_{n}$ ), and may then send price signals to its contracted sources and loads. These signals will arrive during the next timeslot (slot $s_{n+1}$ in this example) but will not take effect, regardless of the contract terms, until the beginning of the following timeslot (slot $s_{n+2}$ ).

\subsubsection{Execution set-up}

At the end of the contracting phase, the agent has knowledge of its current contract commitments, and of the number of customers who have agreed to its offered tariffs. Execution covers some period of time while these contracts are in place. In order to avoid a lengthy period of adjustment at the beginning of each execution phase, a single timeslot $s_{-1}$ is run in execution mode immediately prior to the period that is to be simulated and evaluated. Results of this preliminary timeslot, along with the current date and time, are then made available to the agent, and the agent is given an opportunity to request history and forecast data, to adjust its variable prices, and to trade in the regional exchange, before full execution commences. During this setup interval, energy can be traded for all timeslots starting with $s_{0}$ instead of being restricted to timeslots starting with $s_{1}$, and leadtime restrictions for price changes are waived. This allows the execution phase to begin in a relatively stable state, without requiring agents to spend multiple cycles fine-tuning their balance. 


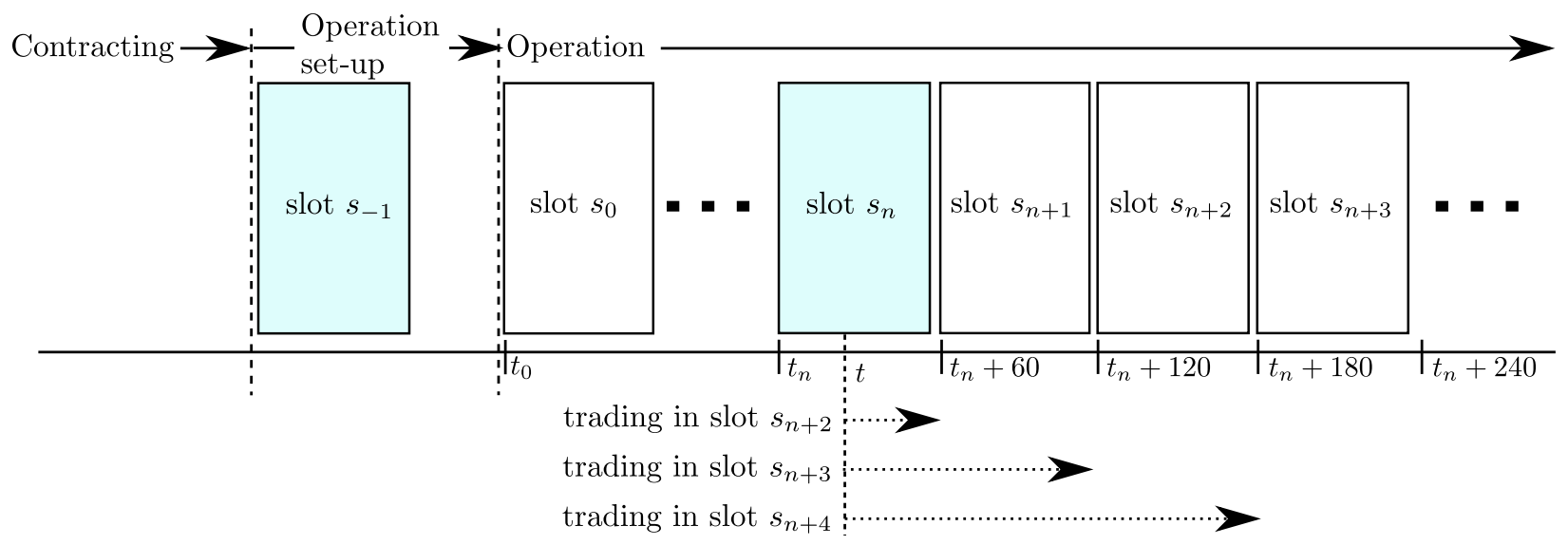

Figure 7: Timeline of interaction between agent and simulation.

\subsubsection{Execution}

After the setup period, beginning at time $t_{0}$, the simulation runs continuously. Agents may trade in the exchange and set variable prices at any time. At the end of each timeslot, the agent will receive a performance report giving the supply and demand volume for each of its contracts and tariffs. For each future timeslot $s \succ s_{n}$ a broker $b$ must maintain a forecast of its total expected load and capacity. Total load is the sum of the expected loads $e_{c}^{\prime}(i, s)$ of each consumer $i$ in the broker $b$ 's consumer portfolio $\mathcal{C}_{b}$ for timeslot $s$. Total production is the sum of expected capacity $e^{\prime} g(j, s)$ for each producer $j$ within its producer portfolio $\mathcal{G}_{b}$. Given this information, the agent's task is to adjust prices, and trade in the regional exchange, in order to achieve expected balance.

\section{Performance evaluation}

In this section we describe in more detail on how to evaluate TAC Energy and its research value, and then we discuss the broker profit calculation and winner determination process.

\subsection{Research value}

With TAC Energy we are building an abstraction of the real world for the particular purposes as outlined before in this paper. We have finished a prototype of the TAC Energy server and agents, and currently we are running a seminar with 16 graduate students who are building broker agents and will compete against each other in an internal competition by the end of the summer. We will use these initial results to create a demo for the workshop on "Trading Agent Design and Analysis (TADA) 2010" at the ACM Electronic Commerce Conference at Harvard University. With the input from the TADA audience and other input, we will finalize our specification and implementation and introduce a full competition system in 2011.

After each round of feedback, especially after the first competition in 2011, we will evaluate the TAC Energy design through the following three questions:

1. How adequate is TAC Energy as a representation of the real world? For instance, we could compare pricing and load balance predictions between TAC Energy and the real world from data available from the MeRegio project.

2. How effectively does TAC Energy support the research agenda of the participating teams? For instance, are teams effective at modeling preferences or price predictions using TAC Energy?

3. How effective is TAC Energy for public policy guidance? Do the suggested solutions provide new insights into real world policy generation? 


\subsection{TAC Energy winner determination}

Within a competition the performance of its participants has to be evaluated and compared at a certain point in time. This is usually accomplished by rank ordering all participants according to one or more defined performance criteria and to declare the best performer in this rank order winner of the competition. This principle also applies to TAC Energy. Consequently this section describes (i) the performance criteria used to rank order the TAC Energy participants, and (ii) the sampling method. Note that a wide range of performance criteria, such as minimzing carbon emissions, maximizing the share of renewable energy, and other factors can be converted to monetary units by introducing taxes and incentives as part of the market structure.

\subsubsection{Performance criteria}

Each TAC Energy participant (broker) is assessed and an overall rank order of all participants is created based on overall profits $p^{\text {profit }}$, calculated as the (monetary) payments, $p^{\text {pay }}$, minus costs, $p^{\text {cost }}$, minus fees, $p^{\text {fee }}$

$$
p^{\text {profit }}=p^{\text {pay }}-p^{\text {cost }}-p^{\text {fee }}
$$

- Payments are monetary transfers from consumers to brokers and are based on the agreed contract conditions and the actual (ex-post) measured energy consumptions of the respective consumers as described in Section 3.2.2.

- Costs are monetary transfers from brokers to producers and are based on the agreed contract conditions between the respective producer and broker and the actual (ex-post measured) energy produced as described in Section 3.2.2.

- Fees are (i) the cost for external balancing power (see Section 3.2.2) used, and (ii) a carbon tax. The carbon tax is a fixed fee (in EUR / $\mathrm{kWh}$ ) for each $\mathrm{kWh}$ of energy produced from non renewable energy sources. The carbon tax remains constant throughout a competition and is publicly announced ahead of the start of the first round.

\subsubsection{Sampling method}

Several randomly chosen timeslots from each each execution phase are selected as "reference timeslots" before a particular competition starts. The chosen timeslots for a particular execution phase are kept secret until that phase ends. Afterwards, profits are calculated for each of the reference timeslots of the particular execution phase and then averaged over all reference timeslots. The individual profits of the reference timeslots as well as the average profit of an execution phase are publicly announced immediately after the phase ends. The overall ranking of brokers is calculated as the average profit over all reference timeslots from all execution phases. These will be ranked to produce the winner ranking at the end of the competition.

\subsection{Initial results from prototype}

At this point, we have implemented a prototype simulation and agent for the execution phase. The simulation consists of a server that models the market along with producers and consumers, connected through the Internet to individual broker agents. Agents are given a portfolio of energy sources and loads to manage, and must sell or acquire energy on the exchange in order to achieve balance. We have not yet implemented price-sensitive consumers or producers. The screenshot in Figure 8 shows the view of one agent at just before 6:00. At this point, we can see that the agent purchased less than the needed power for timeslots 0:00, 1:00, 3:00, and 4:00, and more than needed in the 2:00 timeslot.

The problem the agent must solve is illustrated by the difference between the "forecast" and "demand" curves for the future. The agent sees only the forecast data, of course; the simulator produces the forecast from the actual supply and demand data for the agent's portfolio using the method of Section 3.2.1. Given these forecasts, the agent must acquire (or sell) enough energy, by trading in future timeslots, to achieve balance before each timeslot becomes the current timeslot, as described in Section 4.2. 


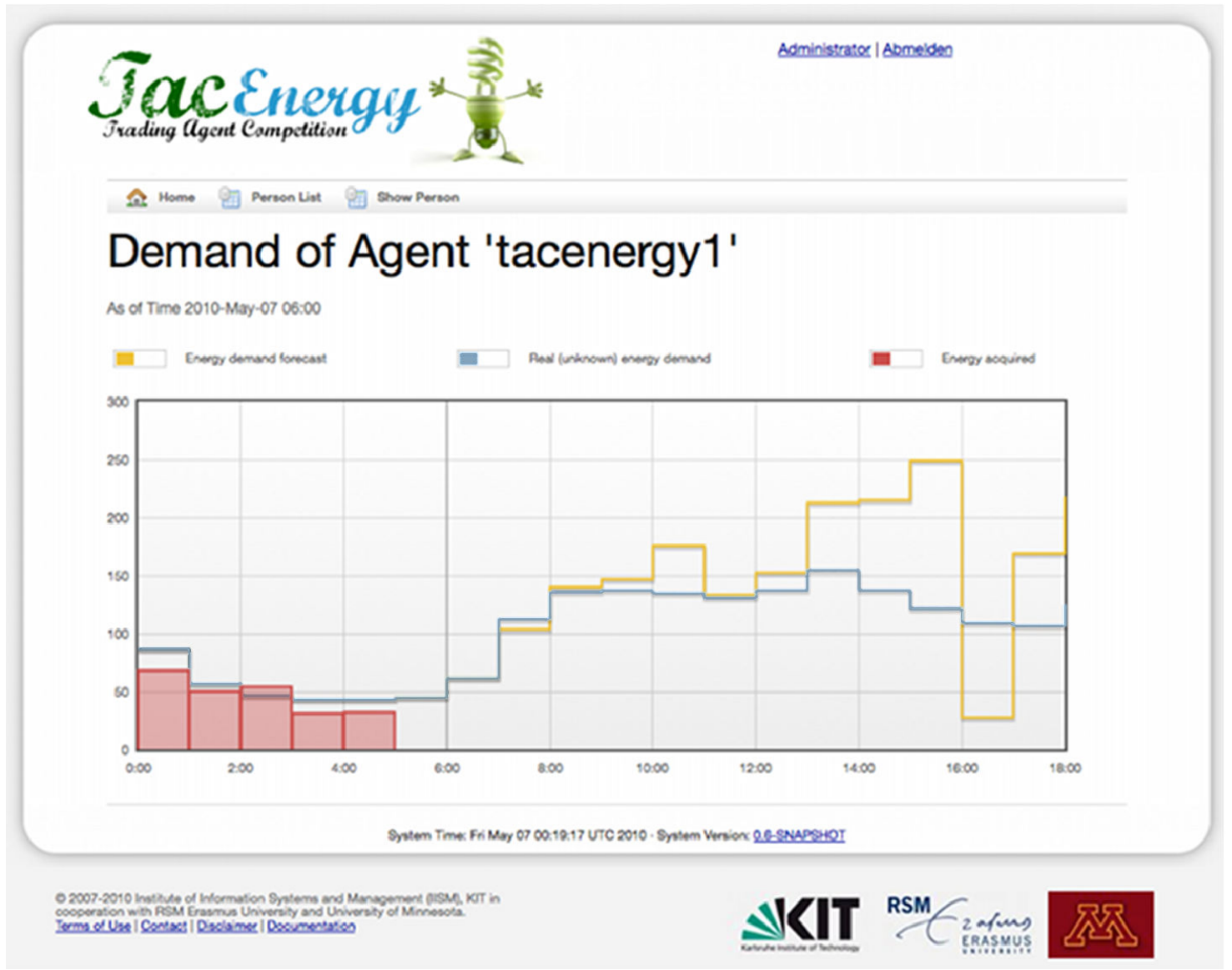

Figure 8: One agent's view during an execution phase.

\section{Conclusion, future work, and research questions}

We are developing of a competitive simulation of a market-based management structure for a local energy grid that would closely model reality by bootstrapping the simulation environment with real historic load, generation, weather, and consumer preference and usage data, gathered from over 900 households in the European MEREGIO project [18], and from the American EPRI/NIST Pacific Northwest project [16]. Such a simulation environment would challenge research teams from around the world to write autonomous agents, or agent-assisted decision support systems for human operators [51], that could operate effectively and profitably in direct competition with each other, while also continuously balancing supply and demand from their portfolios. Teams would also be challenged to exploit the structure of the market, and that structure would be adjusted periodically to defeat counterproductive strategic behaviors. The result would be a body of valuable research data, along with a much higher degree of confidence that such a mechanism could be safely introduced into operating energy systems.

Agents in this market simulation would act as "brokers," purchasing power from distributed sources and from regional energy exchanges, and selling power to consumers and exchanges. These agents must solve a set of complex supply-chain problems in which the product is infinitely perishable, and the environment is subject to high variability and uncertainty (e.g. weather effects, equipment and network outages) and limited visibility. They will operate in a dynamic network at multiple timescales, from negotiating long-term contracts with energy sources and tariffs for customers that balance supply and demand in expectation, to day-ahead spot-market trading, to real-time load balancing. They must deal with individual customers and suppliers, while at the same time aggregating the preferences of large groups of customers into market segments for tariff offerings. They must predict supply and demand over 
monthly, quarterly, and yearly timescales as they develop their portfolios of supplier and customer relationships, and over hours and minutes as they adjust dynamic prices and trade in the spot market in order to maintain real-time balance in the grid.

Competitions have been shown to be an effective way to spur innovation [25, 28, 42]. We expect the primary result of this study to be a clear understanding for policymakers of the capabilities and limitations of open market structures for management of future energy networks that include a variety of distributed sources, including electric vehicles. This simulation will allow such structures to be evaluated in a risk-free environment under a variety of real-world conditions ranging from normal to extreme. The competitive design will effectively uncover potential hazards of proposed market designs in the face of strategic behaviors on the part of the participating agents. The likely effects of various dynamic pricing approaches for consumers and electric vehicle charging can be evaluated. Complex preference models will be developed that have three important properties: attractive to consumers, attractive to brokers, and give brokers sufficient flexibility to balance loads in expectation and in real time. Methods will be developed for charging large numbers of electric vehicles in ways that are both technically feasible and economically attractive to consumers, and that take advantage of the balancing capacities of vehicles.

As a competitive real world testbed, TAC Energy gives ample opportunities for scientists from different disciplines to research and contribute to a variety of important challenges. The initial focus in TAC Energy will be on modeling the behavior and strategies of the broker agents. Competing broker agents may be fully autonomous, or they may be semi-autonomous, interactive decision support systems [8] for human participants. A goal in working with such interactive systems is to discover what types of decision support are most effective at raising the performance of human decision makers in fast-paced environments such as this. Preference modeling [6] must be at the core of the market intelligence service since it has to dynamically cluster customer preferences in order to associate agents with tariffs. Currently, researchers lack a good understanding of how to build these multi-attribute utility functions for real world problems, since often the assumptions of utility theory are violated in real world environments. Can we design heuristics that can help us to approximate utility values for rational agents? Another important research question is the representation of the customer preferences through expressive bidding languages. What is the best format? We may need a more expressive bidding/contracting language in the future, such as described by [36, 41]. Once customers are able to express their preferences in a sophisticated way, we should include reputation measures of broker agent performance. This should have a direct impact on customer preferences. It may become necessary to learn how to merge different preference models, so that the agents can make overall improved rational decisions.

Since the simulation environment and broker agents are subject to high variability, uncertainty and limited visibility, we can study the impact on system stability through exogenous shocks, such as power plant failure, and competition effects among broker agents. We can examine the effects of policy changes, such as taxes and incentives. We can research how rapid technical infrastructure changes affect the environment, and how we can balance these changes in real time. Markets are self-organizing mechanisms, and the TAC Energy environment could be an effective tool for research in self-organizing networks and complex adaptive systems [34].

Our project includes two major phases. In the first phase, we focus our research on the design and development of a competitive simulation for fully autonomous agents, to properly test our market mechanisms and agent strategies. For the second part, we are going to develop a mixed-initiative form of the competition where human players are assisted by intelligent agents (broker agents, grid owners, and customers). This competition will help us to research the important topics of preference representation, and elicitation [6], and the tools that are needed for interactive agent assisted decision recommendation.

\section{Notation}

\begin{tabular}{|l|l|l|}
\hline symbol & explanation & units \\
\hline \hline $\mathcal{B}$ & The set of brokers & \\
$\mathcal{C}$ & Set of energy consumers & \\
$\mathcal{G}$ & Set of energy producers (generators) & time point \\
$t$ & A particular time, typically the current simulation time (now) & minutes \\
$\tau$
\end{tabular}




\begin{tabular}{|l|l|l|}
\hline symbol & explanation & units \\
\hline \hline $\mathcal{S}$ & set of all timeslots & time interval \\
$s_{n}$ & the current timeslot & time point \\
$t_{n}$ & start time of timeslot $s_{n}$ & kilowatt-hours (kwh) \\
$e$ & energy (typically, power integrated over a timeslot) & $\mathrm{kwh}$ \\
$e_{c}$ & load (energy consumed) & $\mathrm{kwh}$ \\
$e_{c}(i, s)$ & (maximum) load of consumer $i$ in timeslot $s$ & $\mathrm{kwh}$ \\
$\epsilon_{c}(i, s)$ & controllable load (balancing capacity) for consumer $i$ in timeslot $s$ & $\mathrm{kwh}$ \\
$\epsilon_{c}(b, s)$ & controllable load (load portion of balancing capacity) for broker $b$ in & \\
& timeslot $s$ & $\mathrm{kwh}$ \\
$e_{g}$ & production (energy generated) & $\mathrm{kwh}$ \\
$e_{g}(j, s)$ & (maximum) generation capacity of producer $j$ in timeslot $s$ & $\mathrm{kwh}$ \\
$\epsilon_{g}(j, s)$ & controllable production (generation portion of balancing power capacity) & \\
& for producer $j$ in timeslot $s$ & $\mathrm{kwh}$ \\
$\epsilon_{g}(b, s)$ & controllable portion of total production capacity for broker $b$ in timeslot $s$ & $\mathrm{kwh}$ \\
$e_{c}^{\prime}$ & forecasted load (energy consumption) & $\mathrm{kwh}$ \\
$e_{c}^{\prime}(i, s)$ & forecasted load of consumer $i$ in timeslot $s$ & $\mathrm{kwh}$ \\
$e_{c}^{\prime}(b, s)$ & overall forecasted load of broker $b$ in timeslot $s$ & $\mathrm{kwh}$ \\
$e_{g}^{\prime}$ & forecasted production capacity (energy production) & $\mathrm{kwh}$ \\
$e_{g}^{\prime}(j, s)$ & forecasted energy production of producer $j$ in timeslot $s$ & $\mathrm{kwh}$ \\
$e_{g}^{\prime}(b, s)$ & overall forecasted energy production of broker $b$ in timeslot $s$ & $\mathrm{kwh}$ \\
$\zeta_{g}(j, s)$ & Forecasting uncertainty for energy output of generator $j$ in timeslot $s$ & $\$$ \\
$p, p^{\prime}$ & prices & $\$ / \mathrm{kwh}$ \\
$p_{j, s}$ & price for production, generator $j$ timeslot $s$ & $\$ / \mathrm{kwh}$ \\
$p_{i, s}$ & price for consumption, consumer $i$ timeslot $s$ & $\mathrm{kwh} / \$$ \\
$P E_{g}(j)$ & Price elasticity for generator $j$ & $\mathrm{kwh}$ \\
$\hat{e}_{g}(j, s, p)$ & Forecast for generator $j$ in timeslot $s$, given production price $p$ & $\mathrm{kwh} / \$$ \\
$P E_{c}(i)$ & Price elasticity for consumer $i$ & $\mathrm{kwh}$ \\
$\hat{e}_{c}(i, s, p)$ & Forecast for consumer $c$ in timeslot $s$, given consumption price $p$ & \\
\hline
\end{tabular}

\section{References}

[1] K.-H. Ahlert and C. Block. Assessing the impact of price forecast errors on the economics of distributed storage systems. In 43rd Hawaii International Conference on System Science (HICSS-43), Hawaii, USA, 2010.

[2] M. Benisch, A. Greenwald, I. Grypari, R. Lederman, V. Naroditskiy, and M. Tschantz. Botticelli: A supply chain management agent designed to optimize under uncertainty. ACM Trans. on Comp. Logic, 4(3):29-37, 2004.

[3] F. Blaabjerg, R. Teodorescu, M. Liserre, and A. Timbus. Overview of control and grid synchronization for distributed power generation systems. IEEE Transactions on Industrial Electronics, 53(5):1398-1409, 2006.

[4] C. Block, F. Bomarius, P. Bretschneider, F. Briegel, N. Burger, B. Fey, H. Frey, J. Hartmann, C. Kern, B. Plail, G. Praehauser, L. Schetters, F. Schoepf, D. Schumann, F. Schwammberger, O. Terzidis, R. Thiemann, C. van Dinther, K. von Sengbusch, A. Weidlich, and C. Weinhardt. Internet der Energie - IKT für Energiemärkte der Zukunft. Bdi-drucksache nr. 418, Bundesverband der Deutschen Industrie e.V. (BDI), 122008.

[5] S. Borenstein, J. B. Bushnell, and F. A. Wolak. Measuring market inefficiencies in California's restructured wholesale electricity market. The American Economic Review, 92(5):1376-1405, 2002.

[6] R. Brafman and C. Domshlak. Preference handling - An introductory tutorial. AI Magazine, 30(1):58-86, 2009.

[7] J. Collins, R. Arunachalam, N. Sadeh, J. Ericsson, N. Finne, and S. Janson. The supply chain management game for the 2006 trading agent competition. Technical Report CMU-ISRI-05-132, Carnegie Mellon University, Pittsburgh, PA, November 2005. 
[8] J. Collins, W. Ketter, and M. Gini. Flexible decision support in dynamic interorganizational networks. European Journal of Information Systems, 19(3), June 2010.

[9] J. Collins, W. Ketter, and N. Sadeh. Pushing the limits of rational agents: the trading agent competition for supply chain management. AI Magazine, 31(2), 2010.

[10] G. Conzelmann, M. North, G. Boyd, R. R. Cirillo, V. Koritarov, C. M. Macal, P. R. Thimmapuram, and T. D. Veselka. Simulating strategic market behavior using an agent-based modeling approach. In 6th IAEE European Energy Conference on Modeling in Energy Economics and Policy, Zurich, 2004.

[11] Technology options for the near and long term. Technical report, U.S. Department of Energy Climate Change Technology Program, September 2006.

[12] J. Duffy. Agent-based models and human subject experiments. In L. Tesfatsion and K. Judd, editors, Handbook of Computational Economics, pages 949-1011. Elsevier, 2006.

[13] EEX. Introduction to exchange trading at EEX on Xetra and Eurex. Technical report, European Energy Exchange AG, January 2008.

[14] EU Commission. Investing in the development of low carbon technologies (SET-plan). Commission Documents COM(2009) 519 final, Commission of the European Communities, October 2009.

[15] EU Commission. Investing in the development of low carbon technologies (SET-plan): A technology roadmap. Commission Staff Working Document SEC(2009) 1295, Commission of the European Communities, October 2009.

[16] D. J. Hammerstrom, R. Ambrosio, J. Brous, T. A. Carlon, D. P. Chassin, J. G. DeSteese, R. T. Guttromson, G. R. Horst, O. M. Järvegren, R. Kajfasz, S. Katipamula, L. Kiesling, N. T. Le, P. Michie, T. V. Oliver, R. G. Pratt, S. Thompson, and M. Yao. Pacific northwest gridwise testbed demonstration projects: The Olympic Peninsula project. Final report, Pacific Northwest National Laboratory, Richland, Washington 99352, October 2007.

[17] N. Hatziargyriou, H. Asano, R. Iravani, and C. Marnay. Microgrids: An overview of ongoing research, development, and demonstration projects. Berkeley Lab Publications LBNL-62937, Lawrence Berkeley National Laboratory, July 2007.

[18] C. Hirsch, L. Hillemacher, C. Block, A. Schuller, and D. Moest. Simulation studies within the MEREGIO field experiment. IT - Information Technology, forthcoming, 2010.

[19] J. Howe. The rise of crowdsourcing. Wired Magazine, 14(6):1-4, 2006.

[20] N. Jennings. On agent-based software engineering. Artificial Intelligence, 117(2):277-296, 2000.

[21] C. M. Jonker and J. Treur. An agent architecture for multi-attribute negotiation. In International joint conference on artificial intelligence, pages 1195-1201, 2001.

[22] P. R. Jordan, B. Cassell, L. F. Callender, and M. P. Wellman. The ad auctions game for the 2009 trading agent competition. Technical report, University of Michigan, Department of Computer Science and Engineering, 2009.

[23] P. R. Jordan, C. Kiekintveld, and M. P. Wellman. Empirical game-theoretic analysis of the TAC supply chain game. In Proc. of the Sixth Int'l Conf. on Autonomous Agents and Multi-Agent Systems, pages 1188-1195, May 2007.

[24] P. Joskow and E. Kahn. A quantitative analysis of pricing behavior in California's wholesale electricity market during summer 2000. NBER Working Paper Series 8157, National Bureau of Economic Research, 2001.

[25] M. Kearns and L. Ortiz. The Penn-Lehman automated trading project. IEEE Intelligent Systems, pages 22-31, 2003. 
[26] W. Ketter, J. Collins, M. Gini, A. Gupta, and P. Schrater. Detecting and forecasting economic regimes in multiagent automated exchanges. Decision Support Systems, 47(4):307-318, 2009.

[27] C. Kiekintveld, J. Miller, P. R. Jordan, L. F. Callender, and M. P. Wellman. Forecasting market prices in a supply chain game. Electronic Commerce Research and Applications, 8(2):63-77, 2009. Special Section: Supply Chain Trading Agent Research.

[28] H. Kitano, M. Asada, Y. Kuniyoshi, I. Noda, E. Osawa, and H. Matsubara. Robocup: A challenge problem for AI and robotics. Lecture Notes in Computer Science, 1395:1-19, 1998.

[29] A. Kox. Erneuerbare energien. European Federation of Energy Traders, January 2009.

[30] J. MacKie-Mason and M. Wellman. Automated markets and trading agents. In L. Tesfatsion and K. Judd, editors, Handbook of computational economics, volume 2, pages 1381-1431. Elsevier, 2006.

[31] R. Marks. Market design using agent-based models. In L. Tesfatsion and K. Judd, editors, Handbook of Computational Economics, pages 1339-1380. Elsevier, 2006.

[32] J. McMillan. Reinventing the bazaar: A natural history of markets. WW Norton \& Company, 2003.

[33] L. Meeus and R. Belmans. Is the prevailing wholesale market design in Europe and North America comparable? In Power Engineering Society General Meeting, 2007. IEEE, pages 1-5, 2007.

[34] J. Miller, S. Page, and B. LeBaron. Complex adaptive systems: An introduction to computational models of social life. Princeton University Press Princeton and Oxford, 2007.

[35] J. Nicolaisen, V. Petrov, and L. Tesfatsion. Market power and efficiency in a computational electricity market with discriminatory double-auction pricing. IEEE Transactions on Evolutionary Computation, 5(5):504-523, 2001.

[36] N. Nisan. Bidding and allocation in combinatorial auctions. Technical report, Institute of Computer Science, Hebrew University, 2000.

[37] J. Niu, K. Cai, S. Parsons, P. McBurney, and E. Gerding. What the 2007 TAC Market Design Game tells us about effective auction mechanisms. Autonomous Agents and Multi-Agent Systems. Special Issue on Market-Based Control of Complex Computational Systems, 2010.

[38] M. North, G. Conzelmann, V. Koritarov, C. Macal, P. Thimmapuram, and T. Veselka. E-laboratories: agent-based modeling of electricity markets. In 2002 American Power Conference, pages 1-19, 2002.

[39] S. Orey and W. Pruitt. Sample functions of the n-parameter wiener process. The Annals of Probability, 1(1):138163, 1973.

[40] I. Sanchez. Short-term prediction of wind energy production. International Journal of Forecasting, 22(1):43-56, January 2006.

[41] T. Sandholm. Algorithm for optimal winner determination in combinatorial auctions. Artificial Intelligence, 135:1-54, 2002.

[42] G. Seetharaman, A. Lakhotia, and E. Blasch. Unmanned vehicles come of age: The DARPA grand challenge. Computer, 39(12):26-29, 2006.

[43] A. Siddiqui, E. Bartholomew, and C. Marnay. Empirical analysis of the spot market implications of price-elastic demand. Berkeley Lab Publications LBNL-56141, Lawrence Berkeley National Laboratory, July 2004.

[44] E. Sodomka, J. Collins, and M. Gini. Efficient statistical methods for evaluating trading agent performance. In Proc. of the Twenty-Second National Conference on Artificial Intelligence, pages 770-775, 2007. 
[45] K. Spees and L. Lave. Impacts of responsive load in PJM: Load shifting and real time pricing. The Energy Journal, 29(2):101-122, 2008.

[46] P. Stone. Multiagent competitions and research: Lessons from RoboCup and TAC. In G. A. Kaminka, P. U. Lima, and R. Rojas, editors, RoboCup-2002: Robot Soccer World Cup VI, pages 224-237. Springer Verlag, Berlin, 2003.

[47] T. Sueyoshi and G. Tadiparthi. An agent-based decision support system for wholesale electricity market. Decision Support Systems, 44(2):425-446, 2008.

[48] J. Sun and L. Tesfatsion. Dynamic testing of wholesale power market designs: An open-source agent-based framework. Computational Economics, 30(3):291-327, 2007.

[49] V. Tamma, S. Phelps, I. Dickinson, and M. Wooldridge. Ontologies for supporting negotiation in e-commerce. Engineering Applications of Artificial Intelligence, 18(2):223-236, March 2005.

[50] L. Tesfatsion. Agent-based computational economics: Growing economies from the bottom up. Artificial Life, 8(1):55-82, 2002.

[51] L. Z. Varga, N. R. Jennings, and D. Cockburn. Integrating intelligent systems into a cooperating community for electricity distribution management. Int. Journal of Expert Systems with Applications, 7(4):563-579, 1994.

[52] D. Veit, A. Weidlich, and J. A. Krafft. An agent-based analysis of the german electricity market with transmission capacity constraints. Energy Policy, 37(10):4132-4144, 2009.

[53] D. von Dollen. Report to NIST on the smart grid interoperability standards roadmap. Technical Report SB134109-CN-0031, Electric Power Research Institute (EPRI), June 2009.

[54] P. Vytelingum, T. D. Voice, S. D. Ramchurn, A. Rogers, and N. R. Jennings. Agent-based micro-storage management for the smart grid. In Proc. of the Ninth Int'l Conf. on Autonomous Agents and Multi-Agent Systems, 2010.

[55] A. Weidlich and D. Veit. A critical survey of agent-based wholesale electricity market models. Energy Economics, 30(4):1728-1759, 2008.

[56] M. P. Wellman, A. Greenwald, and P. Stone. Autonomous Bidding Agents. MIT Press, 2007.

[57] M. Wooldridge and N. Jennings. Intelligent agents: Theory and practice. Knowledge engineering review, 10(2):115-152, 1995.

[58] Z. Zhou, W. Chan, and J. Chow. Agent-based simulation of electricity markets: a survey of tools. Artificial Intelligence Review, 28(4):305-342, 2007. 


\section{Publications in the Report Series Research* in Management \\ ERIM Research Program: "Business Processes, Logistics and Information Systems"}

2009

How to Normalize Co-Occurrence Data? An Analysis of Some Well-Known Similarity Measures

Nees Jan van Eck and Ludo Waltman

ERS-2009-001-LIS

http://hdl.handle.net/1765/14528

Spare Parts Logistics and Installed Base Information

Muhammad N. Jalil, Rob A. Zuidwijk, Moritz Fleischmann, and Jo A.E.E. van Nunen

ERS-2009-002-LIS

http://hdl.handle.net/1765/14529

Open Location Management in Automated Warehousing Systems

Yugang YU and René B.M. de Koster

ERS-2009-004-LIS

http://hdl.handle.net/1765/14615

VOSviewer: A Computer Program for Bibliometric Mapping

Nees Jan van Eck and Ludo Waltman

ERS-2009-005-LIS

http://hdl.handle.net/1765/14841

Nash Game Model for Optimizing Market Strategies, Configuration of Platform Products in a Vendor Managed Inventory (VMI) Supply Chain for a Product Family

Yugang Yu and George Q. Huang

ERS-2009-009-LIS

http://hdl.handle.net/1765/15029

A Mathematical Analysis of the Long-run Behavior of Genetic Algorithms for Social Modeling

Ludo Waltman and Nees Jan van Eck

ERS-2009-011-LIS

http://hdl.handle.net/1765/15181

A Taxonomy of Bibliometric Performance Indicators Based on the Property of Consistency

Ludo Waltman and Nees Jan van Eck

ERS-2009-014-LIS

http://hdl.handle.net/1765/15182

A Stochastic Dynamic Programming Approach to Revenue Management in a Make-to-Stock Production System Rainer Quante, Moritz Fleischmann, and Herbert Meyr

ERS-2009-015-LIS

http://hdl.handle.net/1765/15183

Some Comments on Egghe's Derivation of the Impact Factor Distribution

Ludo Waltman and Nees Jan van Eck

ERS-2009-016-LIS

http://hdl.handle.net/1765/15184

The Value of RFID Technology Enabled Information to Manage Perishables

Michael Ketzenberg, and Jacqueline Bloemhof

ERS-2009-020-LIS

http://hdl.handle.net/1765/15412

The Environmental Gains of Remanufacturing: Evidence from the Computer and Mobile Industry

J. Quariguasi Frota Neto, and J.M. Bloemhof

ERS-2009-024-LIS

http://hdl.handle.net/1765/15912 
Economic Modeling Using Evolutionary Algorithms: The Effect of a Binary Encoding of Strategies

Ludo Waltman, Nees Jan van Eck, Rommert Dekker, and Uzay Kaymak

ERS-2009-028-LIS

http://hdl.handle.net/1765/16014

Language Selection Policies in International Standardization - Perception of the IEC Member Countries

Hans Teichmann and Henk J. de Vries

ERS-2009-031-LIS

http://hdl.handle.net/1765/16038

Dominant Design or Multiple Designs: The Flash Memory Card Case

Henk J. de Vries, Joost P.M. de Ruijter and Najim Argam

ERS-2009-032-LIS

http://hdl.handle.net/1765/16039

Standards Education Policy Development: Observations based on APEC Research

Donggeun Choi, Henk J. de Vries and Danbee Kim

ERS-2009-033-LIS

http://hdl.handle.net/1765/16040

Scheduling deliveries under uncertainty

Adriana F. Gabor, Rommert Dekker, Timon van Dijk, and Peter van Scheepstal

ERS-2009-040-LIS

http://hdl.handle.net/1765/16236

A simple alternative to the $h$-index

Ludo Waltman and Nees Jan van Eck

ERS-2009-043-LIS

http://hdl.handle.net/1765/16556

Disruption Management of Rolling Stock in Passenger Railway Transportation

Lars Kjaer Nielsen and Gabor Maroti

ERS-2009-046-LIS

http://hdl.handle.net/1765/16557

A Temporal Web Ontology Language

Viorel Milea, Flavius Frasincar, and Uzay Kaymak

ERS-2009-050-LIS

http://hdl.handle.net/1765/16794

On the Suboptimality of Full Turnover-Based Storage

Yugang Yu and René B.M. de Koster

ERS-2009-051-LIS

http://hdl.handle.net/1765/16898

An Inventory Model for Slow Moving Items Subject to Obsolescence

Cerag Pince,and Rommert Dekker

ERS-2009-053-LIS

http://hdl.handle.net/1765/17197

A Multi-Agent Energy Trading Competition

Carsten Block, John Collins, Wolfgang Ketter, and Christof Weinhardt

ERS-2009-054-LIS

http://hdl.handle.net/1765/17337

* A complete overview of the ERIM Report Series Research in Management: https://ep.eur.nl/handle/1765/1

ERIM Research Programs:

LIS Business Processes, Logistics and Information Systems

ORG Organizing for Performance

MKT Marketing

F\&A Finance and Accounting

STR Strategy and Entrepreneurship 